Owen Eli Ceballos-Mina* Luis Enrique Santiago-Ayala*

Recibido: 7 de septiembre 2018

Concepto de evaluación: 15 de febrero de 2019

Aprobado: 12 de diciembre de 2019

Artículo de investigación

(C) 2019 Universidad Católica de Colombia.

Facultad de Ciencias

Económicas y Administrativas.

Todos los derechos reservados
Finanz. polit. econ., ISSN: 2248-6046, Vol. 11, N. ${ }^{\circ} 2$, julio-diciembre, 2019, pp. 299-320

http://doi.org/10.14718/revfinanzpolitecon.2019.11.2.5

\title{
Efectos de las tarjetas de crédito en la estructura de consumo y la desigualdad de los hogares mexicanos
}

\section{RESUMEN}

En este artículo se analizan los efectos de la tenencia de tarjeta de crédito (TC) sobre la estructura y la distribución del gasto de las familias mexicanas en el 2016. Para ello, se usan regresiones cuantílicas en dos etapas para estimar modelos de los determinantes del consumo y se instrumenta el efecto de las TC por categoría de gasto. Se evidencia así que estas tienen un efecto positivo sobre el consumo agregado, guiado principalmente por el aumento del gasto en salud y rubros menos básicos como vestido, comunicaciones y esparcimiento. A su vez, se encontró que no tienen efectos significativos sobre los gastos en educación y bienes durables. Los efectos de las TC son mayores en la parte alta de la distribución de consumo, por lo que pueden cuestionarse dichos efectos sobre la reducción de la desigualdad y el bienestar futuro de las familias, dadas las condiciones del proceso de inclusión financiera en el país.

Palabras clave: bienestar, consumo, desigualdad, hogares mexicanos, inclusión financiera, tarjetas de crédito.

\section{JEL Classification: C21, D12, D14, G20}

Cómo citar este artículo / To reference this article / Para citar este artigo:

Ceballos-Mina, O., E. \& Santiago-Ayala, L., E. (2019). Efectos de las tarjetas de crédito en la estructura de consumo y la desigualdad de los hogares mexicanos. Revista Finanzas y Política Económica, 11(2), 299-320. doi: http://dx.doi.org/10.14718/ revfinanzpolitecon.2019.11.2.5

\section{The effects of credit cards on consumption structure and inequality in Mexican households}

* Doctor en Economía por El Colegio de México A.C.; docente-investigador del Departamento de Economía de la Universidad Autónoma Metropolitana, Azcapotzalco. Correo electrónico: oecm@azc.uam.mx (D) https://orcid.org/ 0000-0003-1931-8388

** Licenciado en Economía por la Universidad Autónoma Metropolitana; estudiante de la Maestría en Economía de EI Colegio de México A. C. Correo electrónico: luis.santiago@colmex.mx (D) https://orcid.org/ 0000-0001-8810-8427

\section{ABSTRACT}

This paper analyzes the effects of credit card holding on the structure and distribution of household expenditure in Mexico in 2016. To the effect, two-stage quantile regressions are used to estimate models for consumption determinants, using instrumental variables on credit card holding. The study evidences that credit cards have a positive effect on aggregate consumption, driven mainly by increased health expenditure and items such as clothing, 
communications, and entertainment. Results show that credit card holding does not have statistical effects on education expenditure, nor on durable goods consumption. Also, the effects of credit cards are greater on the top of consumption distribution; thus, the effects of such financial services on the reduction of inequality and the future well-being of families are questioned, given that preconditions for financial inclusion have not been enough.

Keywords: Consumption, credit cards, financial inclusion, inequality, Mexican household, well-being.

\section{Efeitos dos cartões de crédito na estrutura de consumo e desigualdade dos lares mexicanos}

\section{RESUMO}

Neste artigo, são analisados os efeitos da posse de cartão de crédito na estrutura e distribuição das despesas das famílias mexicanas em 2016. Para isso, são usadas regressões quantílicas em duas etapas para estimar modelos dos determinantes do consumo e é instrumentalizado o efeito de ter cartão de crédito por categoria de gasto. Assim, torna-se evidente o efeito positivo sobre o consumo agregado, orientado principalmente pelo aumento do gasto em saúde e despesas menos básicas como vestimenta, comunicações e entretenimento. Por sua vez, foi constatado que não tem efeitos significativos sobre os gastos em educação e bens duráveis. Os efeitos de possuir cartão de crédito são maiores na parte alta da distribuição de consumo, portanto esses efeitos sobre a redução da desigualdade e do bem-estar futuro das famílias podem ser questionados, tendo em vista as condições do processo de inclusão financeira no país.

Palavras-chave: bem-estar, cartões de crédito, consumo, desigualdade, inclusão financeira, lares mexicanos. 


\section{INTRODUCCIÓN}

Uno de los temas que causa mayor interés entre científicos y autoridades en Latinoamérica es el de las estrategias de política pública para la inclusión financiera. Parece existir el consenso de que el desarrollo financiero y sus servicios asociados tienen efectos positivos sobre el crecimiento económico y el bienestar de la población (Roa, 2013; Beck, Demirgüç-Kunt y Levine, 2007; Levine, 2005). Adicional a la riqueza, el capital humano y el ciclo de vida como principales determinantes del comportamiento del gasto, también se han incorporado los servicios financieros como elementos activos del proceso de suavización intertemporal (DemirgüçKunt y Klapper, 2012; Muñoz, 2 004). La literatura sobre el tema argumenta que el uso de los servicios financieros formales representa la oportunidad de mejorar los niveles de bienestar de los más pobres e incluso reducir la desigualdad en favor de los grupos más vulnerables por conducto de la inversión.

El país no ha sido indiferente ante la relación sugerida entre inclusión financiera y bienestar; desde hace algunos años las autoridades mexicanas iniciaron esfuerzos para promover y dar seguimiento a los servicios financieros ${ }^{1}$. En específico, en el 2013 se aprobó una reforma financiera que tiene entre sus objetivos bajar los costos e incrementar el acceso a productos y servicios (Rodríguezy Dorantes, 2016). La política pública mexicana se ha orientado a sentar las bases de un desarrollo financiero que incorpore a la mayoría de la población; sin embargo, dicha estrategia de carácter expansivo en la oferta de servicios aún no ha logrado el impacto deseado (Woodruff y Martínez, 2009; Cotler y Rodríguez-Oreggia, 2009); aunque la penetración financiera va en aumento, la importante brecha entre sectores menos favorecidos y los de mayores recursos parece mantenerse.

1 Políticas como la Ley de Ahorro y Crédito Popular del 2001, el mandato de oferta obligatoria de cuentas básicas para las instituciones bancarias del 2007, la creación de la Comisión Nacional para la Inclusión Financiera (CONAIF) del 2011 y la realización de encuestas nacionales para la inclusión financiera (ENIF) en el 2012 y el 2015, entre otros, son algunos de los esfuerzos gubernamentales e institucionales que muestran el interés por el tema del desarrollo y la inclusión financiera en el país.
En México ha habido una rápida expansión de algunos servicios financieros mediante procesos como la bancarización inducida o la misma dinámica de mercado de servicios como las tarjetas de crédito (TC) ${ }^{2}$. Si bien en el 2015 más del $32 \%$ de la población del país se reportó sin acceso a servicios financieros formales, la Encuesta Nacional para la Inclusión Financiera (ENIF) anunció un incremento de más $10 \%$ de la población con tenencia de cuentas bancarias entre el 2012 y el 2015. De igual forma, la Comisión Nacional Bancaria y de Valores (CNBV) contabilizó en diciembre del 2016 cerca de 24,4 millones de TC y un incremento en más de 285.000 contratos solo en el primer cuatrimestre del 2017. Sin duda, las TC son el servicio crediticio formal con mayor penetración entre los sectores de la población mexicana, ante lo cual la pregunta inmediata es: ¿cuál es el efecto del uso de estos servicios financieros?

Pese a la relevancia de la inclusión financiera como estrategia de desarrollo y su auge en el ámbito nacional desde la perspectiva de política pública, pocos estudios en México presentan un análisis de los efectos del uso de servicios financieros formales sobre el consumo de los hogares. En este artículo se analizan los efectos de las TC sobre los principales rubros de consumo y la distribución del bienestar derivada de estos servicios. Asimismo, se plantean modelos de determinantes del gasto, incorporando los efectos de la tenencia de TC y teniendo en cuenta la riqueza, el ciclo de vida y el capital humano del hogar. Con datos de la Encuesta Nacional de Ingresos y Gastos de los Hogares (ENIGH) del 2016, se estiman regresiones cuantílicas para ver las repercusiones de las TC sobre la distribución del gasto. También se instrumenta el conjunto de nuestras regresiones para depurar y confirmar los efectos de las TC sobre la estructura del consumo de los hogares cuando se corrige el problema de selección endógena vinculado a la tenencia del servicio financiero.

Las estimaciones muestran efectos positivos del uso de las TC sobre el conjunto de gasto monetario;

2 Prácticas como la dispersión de apoyos de programas públicos mediante cuentas bancarias constituyen una estrategia común en el proceso de bancarización del país. 
sin embargo, no se identifican efectos significativos de las TC sobre rubros como la educación, los bienes durables y los alimentos, que son fundamentales en el bienestar futuro y en la acumulación de capital humano. En lugar de ello, se incrementa el consumo de bienes menos básicos como calzado, vestido, transporte, comunicaciones y esparcimiento. Excepto por el comportamiento del gasto en salud, se identificó que los efectos de las TC son mayores en la parte alta de la distribución de consumo, mientras que las familias con menos recursos incluso pagan más intereses por el financiamiento. El uso de las TC tiene efectos limitados en la acumulación de capital humano y puede empeorar las condiciones de la población de menos recursos ante sus bajas capacidades financieras.

Los acelerados procesos de bancarización y de acceso a servicios financieros no son garantía por sí solos de las mejoras en el bienestar de toda la población y especialmente de la de menos recursos. La hipótesis principal de este ensayo es que la oferta de servicios que conduce el proceso de inclusión financiera posee una dinámica superior a la de creación del capital humano que se necesita del lado de la demanda para que la estrategia logre los efectos deseados sobre el bienestar. La rápida expansión de la oferta de servicios, motivada por las expectativas de ganancia de las instituciones bancarias, pone productos financieros al alcance de sectores de la población sin la educación y capacidad financiera suficiente para crear una cultura alrededor del uso de estos instrumentos.

\section{SERVICIOS FINANCIEROS EN EL CONSUMO}

Los estudios sobre el financiamiento del consumo de las familias y sus determinantes son temas del pasado, presente y futuro de la rama económica. Desde la investigación de Engel en 1857 acerca de la proporción de ingresos asignada en diferentes categorías de bienes, el consumo ha ocupado un papel protagónico como medida de bienestar de los hogares, más allá de la discusión de si es mejor indicador que el ingreso (Engel y Kneip, 1996; Medina, 1998). De las incursiones de Engel sobreviene la idea de que incrementos del ingreso en el hogar modifican la estructura de consumo, de modo tal que el aumento generalizado del gasto es decreciente en los artículos de primera necesidad y creciente en bienes menos básicos y de lujo (García, 2013; Martínez y Villezca, 2005).

La Organización para la Cooperación y el Desarrollo Económicos (OCDE, 2015) sugiere que es posible dar seguimiento al desarrollo, crecimiento y bienestar económico por medio de rubros relevantes de consumo, como el gasto en salud, educación y en bienes duraderos. Mientras la inversión en capital humano y en salud posee retornos inmediatos y futuros sobre el flujo de ingresos del hogar (Becker y Tomes, 1986; Attanasio y Székely, 1999; Van Gameren, 2008), autores como Bernal (2007), Zimmerman y Carter (2003), Berti (2001) y Schreiner et al. (2001) plantean que los hogares de menos recursos usan la compra y acumulación de bienes durables como una estrategia de bienestar futuro ante la ausencia de ahorro monetario para el financiamiento.

La literatura sobre el consumo y sus determinantes remite a los trabajos seminales de Friedman (1957) y Modigliani y Brumberg (1954), con la hipótesis del ingreso permanente (HIP) y el modelo del ciclo de vida (MCV), respectivamente. La idea central desde estos enfoques es que el consumidor maximiza una función de bienestar que depende de su consumo presente y futuro, sujeto a una restricción de riqueza en función de una dotación inicial y de sus ingresos esperados (Liquitaya, 2011). Una visión sintética del MCV plantearía que, dependiendo de la fase del ciclo de vida, los hogares buscan suavizar su consumo; sin embargo, las pruebas empíricas del MCV en México han mostrado la no suavización del consumo como resultado de las restricciones de liquidez y de la falta de acceso a los servicios financieros (Ceballos, 2018; Campos y Meléndez, 2013; Sandoval, 2013). Así, pues, desde el MCV y la HIP, la literatura económica ha consensuado al ahorro y al crédito como variables fundamentales de las estrategias de financiamiento, reducción de la incertidumbre y suavización del consumo de los hogares (Aportela, 1999, 2001; 
Beck, Demirgüç-Kunt y Levine, 2007; DemirgüçKunt, Beck y Honohan, 2008; Levine, 2005; Morfín, 2009; Vonderlack y Schreiner, 2001; Castellanos y Garrido, 2010).

Además del ingreso y las variables financieras, la edad del jefe de hogar como representación del ciclo de vida y el nivel de escolaridad también son considerados como determinantes principales del consumo. Algunos estudios se han centrado en el vínculo entre el consumo y el capital humano; por ejemplo, Attanasio y Székely (1999) establecen que los hogares que invirtieron más en educación esperan mayores niveles de bienestar por conducto del ahorro. En general, la literatura empírica sobre el consumo destaca la importancia de controlar, por los aspectos demográficos y de ciclo de vida familiar, aspectos de capital humano y los aspectos financieros y de riqueza de los hogares (Muñoz, 2004).

El sector de la rama económica que se ha centrado en los efectos de desarrollo financiero sobre el crecimiento sugiere que mejoras en el acceso y profundización de los servicios financieros tiene efectos positivos sobre la estabilización del consumo y sobre los niveles de riqueza de los hogares (Levine, 2005; Beck, Demirgüç-Kunty Levine, 2007; Demirgüç-Kunt, Beck y Honohan, 2008; Demirgüç-Kunt y Levine, 2009). En favor de esta hipótesis, Villarreal (2014), Galor y Zeira (1993) y Becker y Tomes (1986), entre otros autores, plantean que el acceso a servicios financieros puede mejorar el bienestar de las familias e incluso reducir la desigualdad por vía de la inversión en capital humano. Este argumento yace sobre la idea implícita de que no solo se espera un retorno presente del acceso a los servicios financieros, sino también un retorno futuro; con ello, se esperarían efectos positivos de estos servicios sobre los rubros de consumo que determinan los niveles de bienestar presente y los rubros asociados al capital humano, como la salud y la educación, al igual que cambios en bienes de inversión o de consumo durable.

El incremento del acceso a los servicios y productos financieros podría no ser estrategia de política pública suficiente para alcanzar los cambios deseados en el bienestar de la población. En este sentido, existe una importante parte de la literatura económica que hace referencia a los efectos del capital humano sobre el ámbito financiero. Un tema que recibe mucha atención internacional en la actualidad es el de los conocimientos o educación financiera (Lusardi y Mitchell, 2007, 2011, 2014; Behrman, Mitchell, Soo y Bravo, 2010); la idea central de este enfoque es que el medio financiero es cada vez más complejo, por lo que los individuos necesitan mayor conocimiento, información y herramientas básicas para tomar decisiones óptimas sobre la administración de su riqueza, consumo y bienestar.

Estudios empíricos relacionados con la educación financiera en México identifican efectos positivos del alfabetismo financiero sobre las decisiones de ahorro, crédito, administración de la riqueza y ahorro para el retiro de las personas (Duarte y Hasting, 2009; Hasting y Tejada, 2008; González y Villagómez, 2014). Pero también hay pruebas que muestran que el proceso de alfabetismo financiero en el país ha sido lento y que sus avances no han sido suficientes para mejorar los niveles de cultura financiera (Amezcua, Arroyo y Espinosa, 2014). Los bajos niveles de educación financiera se reflejan en la falta de planeación, los malos hábitos en el uso de servicios, el desconocimiento de derechos y obligaciones frente a los contratos y la baja participación en algunos productos y servicios financieros (Urbiola, 2011).

La problemática de la educación financiera empieza a atenderse, desde la perspectiva internacional, mediante los diagnósticos y recomendaciones de organismos internacionales como el Comité Económico Social Europeo (CESE) o el Centro de Estudios Monetarios Latinoamericanos (CEMLA). En general, estas organizaciones coinciden en que la educación financiera es un determinante fundamental del uso responsable de productos financieros y que es un instrumento estratégico para la población en su entorno personal y familiar (CESE, 2011). Estas organizaciones se han preocupado desde entonces por promocionar y difundir las mejores prácticas sobre alfabetismo financiero en sus respectivas regiones. En Latinoamérica se han liderado iniciativas relacionadas con el seguimiento y promoción de la educación financiera desde las acciones de los bancos centrales y los comités designados en cada país. 
El consenso es la necesidad de diversificar y adaptar las prácticas de mayor éxito para generar las capacidades financieras adecuadas (Alonso et al., 2014).

Esta revisión de la literatura pone de relieve la necesidad de abordar la problemática de la inclusión financiera del país desde una perspectiva con varias dimensiones. La provisión y acceso a los servicios para el desarrollo financiero es importante, pero el capital humano es prioridad en el proceso de desarrollo financiero para la consecución de los objetivos deseados sobre el bienestar. El rol del capital humano se vuelve fundamental en el proceso de inclusión financiera; en él puede ser identificado cómo se afecta la acumulación de capital humano durante el proceso y su interacción con algunos servicios financieros como las TC.

\section{RUBROS DE CONSUMO Y TARJETAS DE CRÉDITO}

En este ejercicio se propone una agrupación de los principales rubros de gasto con base en la aproximación al bienestar usada por la OCDE (2015) en su Iniciativa para una Vida Mejor. Dicha investigación vincula al gasto con los niveles de bienestar presente y destaca que el capital natural, el capital humano y el capital social son fundamentales en la determinación del bienestar futuro. La organización propone un índice compuesto por varios rubros, entre los que, además del ingreso, se destacan la inversión en educación, en salud y vivienda como elementos esenciales del bienestar ${ }^{3}$.

Para el presente análisis empírico de los efectos de las tarjetas de crédito en los rubros de

$3 \quad$ Con base en la propuesta de la OCDE, los grupos de gastos que representan la estructura de consumo en este análisis son: a) gasto monetario: suma del gasto en alimentos, bienes durables, educación, salud y gasto en otros bienes; b) gasto en alimentos: gastos en bienes de consumo no duradero que realizan día a día los integrantes del hogar en alimentos y bebidas; c) gasto en bienes durables: gastos en bienes de consumo duraderos, que incluyen el pago por adquisición de vehículo y vivienda (pago de hipoteca); d) gasto en educación: gasto en servicios y artículos para la educación; e) gasto en salud: gasto en atenciones médicas, como consultas, visitas al hospital, ambulancias y medicinas; f) gasto en otros bienes: gasto en transporte y comunicación cuidado de la vivienda, vestido, calzado y esparcimiento. consumo y la desigualdad de los hogares, se usa la Encuesta Nacional de Ingresos y Gastos de los Hogares del 2016, publicada por el Instituto Nacional de Estadística, Geografía e Informática (INEGI). La encuesta tiene un tamaño de muestra de 70.311 hogares y captura la evolución de los principales indicadores de ingresos y gastos de las familias mexicanas. En la figura 1, sobre la densidad del logaritmo del gasto monetario, una primera observación del comportamiento sugiere que los hogares con TC poseen mayor nivel de consumo agregado frente a aquellas familias sin el servicio financiero, cuando no se tiene en cuenta ninguna otra característica del hogar.

Figura 1.

Gasto total por tenencia de TC

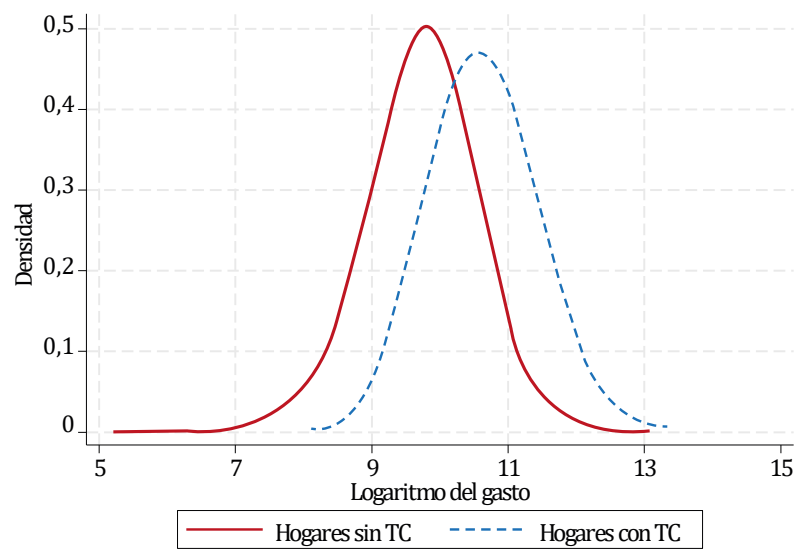

Fuente: cálculos propios con datos de la ENIGH 2016.

La tabla 1 presenta la estructura del gasto de las familias mexicanas en el 2016, según la tenencia o no de TC en el hogar y por quintiles de ingreso. Se observa que los hogares con TC — sin importar el quintil de ingreso - tienen mayor gasto monetario que aquellos sin el servicio financiero (como anticipaba la figura 1). En cuanto a los demás rubros de consumo, la proporción del gasto en alimentos de los hogares con TC es menor frente a los hogares sin $\mathrm{TC}$, mientras el gasto en otros bienes como vestido, transporte y comunicaciones es mayor en los hogares con el servicio financiero. Por su parte, los gastos relacionados con la inversión en bienes durables, educación y salud —asociados al bienestar futurotambién parecen ser mayores en los hogares con TC. 
Tabla 1.

Estructura del gasto de hogares con y sin tarjeta de crédito (TC)

\begin{tabular}{|c|c|c|c|c|c|c|c|c|c|c|}
\hline \multirow{3}{*}{ Grupo de gasto } & \multicolumn{10}{|c|}{ Quintiles de ingreso } \\
\hline & \multicolumn{2}{|c|}{ I } & \multicolumn{2}{|c|}{ II } & \multicolumn{2}{|c|}{ III } & \multicolumn{2}{|c|}{ IV } & \multicolumn{2}{|c|}{$\mathbf{V}$} \\
\hline & Sin TC & Con TC & Sin TC & Con TC & Sin TC & Con TC & Sin TC & Con TC & Sin TC & Con TC \\
\hline Gasto en alimentos (\%) & 47,5 & 39,9 & 41,8 & 33,6 & 37,9 & 31,9 & 33,6 & 29,7 & 26,6 & 21.2 \\
\hline Gasto en bienes durables (\%) & 1,0 & 3,1 & 2,0 & 4,1 & 3,1 & 5,6 & 4,6 & 6,5 & 6,3 & 9,1 \\
\hline Gasto en educación (\%) & 4,7 & 4,9 & 6,5 & 5,4 & 7,0 & 5,8 & 7,4 & 6,7 & 8,6 & 8,9 \\
\hline Gasto en Salud (\%) & 2,5 & 7,9 & 2,1 & 4,0 & 2,1 & 2,1 & 1,9 & 2,5 & 2,3 & 3,0 \\
\hline Gasto en otros bienes (\%) & 44,1 & 49,9 & 47,4 & 52,6 & 49,7 & 54,3 & 52,3 & 54,3 & 55,9 & 57,3 \\
\hline $\begin{array}{l}\text { Monto total de gasto monetario } \\
\text { (valores trimestrales a pesos de } \\
\text { marzo del 2018) }\end{array}$ & 10.519 & 18.566 & 15.923 & 20.852 & 21.225 & 26.035 & 28.278 & 35.203 & 48.797 & 76.177 \\
\hline Gasto/ingreso (\%) & 98,0 & 151,0 & 79,0 & 101,0 & 71,0 & 85,0 & 64,0 & 78,0 & 52,0 & 49,0 \\
\hline Pago de TC/gasto con TC (\%) & & 68,5 & & 112,0 & & 116,0 & & 155,0 & & 215,0 \\
\hline Observaciones & 13.825 & 238 & 13.504 & 558 & 13.103 & 959 & 12.501 & 1561 & 10362 & 3700 \\
\hline
\end{tabular}

Fuente: cálculos propios con datos de la ENIGH 2016.

Otra observación relevante es que la proporción de gasto con respecto al ingreso siempre es mayor en los hogares con TC que en los hogares sin el servicio; incluso en los dos primeros quintiles de ingreso se observa que el gasto es mayor que el ingreso del hogar. La tabla 1 también muestra que los hogares de los quintiles más bajos siempre pagan una menor proporción de lo que gastan con sus TC al final del trimestre, lo cual sugiere que los hogares con mayores recursos parecen usar las TC más como un medio de pago que como medio de financiamiento, mientras las partes bajas de la distribución pagan mayores intereses dada la menor proporción de abono a su deuda.

Los datos de la ENIGH 2016 permiten calcular que más de la mitad de los hogares con TC usan dicho servicio para hacer compras en rubros como vestido, calzado, transporte, comunicaciones y otros gastos no básicos, mientras solo una cuarta parte de los hogares con TC la usan para comprar alimentos, pagar bienes durables, educación o salud. Del total del gasto hecho con TC, más del $63 \%$ es dedicado al gasto en bienes como transporte, comunicaciones, vestido, calzado y esparcimiento, poco más de $20 \%$ es dedicado al gasto en alimentos, mientras solo $1 \%$ es destinado al gasto en educación, $3 \%$ al gasto en salud y 3,5\% al gasto en bienes durables. En general, este rápido vistazo sobre los datos sugiere que efectivamente hay mayor consumo en los hogares con TC; sin embargo, no es claro que el gasto adicional esté asociado con rubros de consumo que contribuyan al bienestar futuro.

\section{TARJETAS DE CRÉDITO EN LA DISTRIBUCIÓN DE GASTO}

La literatura de este ensayo sugiere que la riqueza, el capital humano y el ciclo de vida son los principales determinantes del consumo de las familias. En este apartado se hace una revisión empírica de dicho conjunto de determinantes, incluyendo como variable de interés la tenencia de TC y sus efectos a lo largo de la distribución del gasto. Para ello, se hace una breve descripción metodológica de la técnica de regresión cuantílica y luego se presentan las estimaciones resultantes del modelo por categoría de gasto.

\section{Regresión cuantílica}

Varios economistas coinciden en que una buena estrategia para estimar los efectos de los determinantes del consumo sería el modelo de regresión lineal; pero para observar cómo cambian los efectos a lo largo de la distribución, en lugar de estimar el valor medio por mínimos cuadrados ordinarios (MCO), resulta conveniente usar la regresión cuantílica. Este método 
minimiza las desviaciones absolutas de los errores, ponderando con pesos asimétricos por cada cuantil de gasto (Koenker y Basset, 1978; Sánchez y Vicéns, 2012). Dado que un cuantil se refiere a la proporción de datos por debajo de una medida $\theta$, entonces el modelo propuesto tiene la siguiente forma:

$Y_{i}=X_{i} \beta_{\theta}+u_{\theta i}$

Donde $Y_{i}$ es el gasto total o el rubro de gasto por explicar; $X_{i}$ es la matriz del conjunto de determinantes que incluye la tenencia de tarjetas de crédito; $\beta_{\theta}$ es el parámetro por estimar, correspondiente al cuantil de gasto $\theta ; \mathrm{y} u_{\theta i}$ es una perturbación aleatoria que, de forma análoga al modelo regresión lineal clásico, debe cumplir con el supuesto $E\left(u_{\theta i} \mid X_{i}\right)=0$. La estimación de los parámetros de este modelo resulta de resolver el problema:

$\min _{\beta_{\theta} \in \mathbb{R}}\left[\sum_{y_{i} \geq X_{i} \beta_{\theta}} \theta\left|y_{i}-X_{i} \beta_{\theta}\right|+\sum_{y_{i}<X_{i} \beta_{\theta}}(1-\theta)\left|y_{i}-X_{i} \beta_{\theta}\right|\right]$ [2]

La tabla 2 presenta las variables usadas para estimar la ecuación [1]. La estructura de gasto total de los hogares es representada en cinco categorías: alimentos, bienes durables, educación, salud y otros bienes. Se estiman seis modelos de consumo por medio de la regresión cuantílica, usando el mismo conjunto de variables explicativas en cada uno.

Tabla 2.

Variables para la estimación por cuantiles de gasto

\begin{tabular}{|c|c|c|}
\hline $\begin{array}{c}\text { Variables } \\
\text { dependientes (Yi) }\end{array}$ & \begin{tabular}{|c|} 
Conjunto de \\
determinantes
\end{tabular} & $\begin{array}{c}\text { Variables explicativas } \\
\text { (Xi) }\end{array}$ \\
\hline-- & \multirow{2}{*}{ Riqueza } & $\begin{array}{l}\text { Tenencia de tarjeta de } \\
\text { crédito }\end{array}$ \\
\hline-- & & Ingreso corriente \\
\hline $\begin{array}{l}\text { Gasto monetario } \\
\text { total }\end{array}$ & $\begin{array}{c}\text { Capital } \\
\text { humano }\end{array}$ & $\begin{array}{c}\text { Años de educación del } \\
\text { jefe de hogar }\end{array}$ \\
\hline Gasto en alimentos & \multirow{4}{*}{$\begin{array}{l}\text { Ciclo de vida } \\
\text { familiar }\end{array}$} & Edad del jefe de hogar \\
\hline $\begin{array}{l}\text { Gasto en bienes } \\
\text { durables }\end{array}$ & & Edad del jefe al cuadrado \\
\hline Gasto en educación & & Tamaño de hogar \\
\hline Gasto en salud & & Menores de 12 años \\
\hline $\begin{array}{l}\text { Gasto en otros } \\
\text { bienes }\end{array}$ & \multirow{3}{*}{$\begin{array}{l}\text { Otros } \\
\text { controles }\end{array}$} & Sexo del jefe de hogar \\
\hline-- & & $\begin{array}{l}\text { Localización urbana/ } \\
\text { rural }\end{array}$ \\
\hline-- & & Nivel socioeconómico \\
\hline
\end{tabular}

Fuente: elaboración propia.

\section{Determinantes del gasto y tarjetas de crédito por cuartiles}

Sin importar el rubro de gasto analizado, la tabla 3 muestra el gran poder explicativo del logaritmo del ingreso a lo largo de la distribución de gasto. Autores como Ceballos (2018), Sandoval (2013), Mejía (2008) y Villagómez y Zamudio (2000) han evidenciado esta alta correlación de forma previa. Cabe mencionar que todas las agrupaciones de determinantes en la tabla 2 participan en la explicación del consumo; a pesar de las diferencias que se observan entre los cuartiles, después del ingreso, el tamaño de hogar, los años de educación y la edad del jefe son las variables que más aportan en la determinación de los rubros de gasto de los hogares.

Las regresiones cuantílicas sugieren efectos significativos de la tenencia de TC sobre la explicación del consumo. Igual que lo comprende Villarreal (2014), se encuentran efectos positivos sobre el total del conjunto de gasto monetario, pero en este caso los coeficientes son crecientes a lo largo de la distribución. Los efectos de alrededor de 1,3 y hasta 7,3 puntos porcentuales entre el primer y el tercer cuartil indican que los hogares que más incrementan su consumo con las TC son los de la parte alta de la distribución. Este efecto positivo es conducido principalmente por el incremento del gasto en salud (cerca de 15\%) y el gasto en otros bienes menos básicos como ropa, calzado, esparcimiento, limpieza, comunicaciones y transporte (alrededor de 5\%). El incremento del gasto en salud es la única aportación de las TC al capital humano; en los bienes durables no se observan efectos significativos, en el gasto en educación los efectos de las TC son incluso negativos, mientras para el gasto en alimentos los efectos de las TC son no significativos. Por su parte, los paneles de la figura 2 representan los coeficientes de las TC resultado de las regresiones cuantílicas por cada uno de los rubros de gasto analizados en este ejercicio.

En general, pese al comportamiento creciente en el que los deciles de gasto más altos tienen mayores efectos de las TC a lo largo de la distribución, solo en el caso del total de gasto monetario y en el de otros bienes como vestido, transporte y comunicaciones hay 
Tabla 3

Determinantes del consumo por rubros y cuartiles de gasto

\begin{tabular}{|c|c|c|c|c|c|c|c|c|c|}
\hline \multirow{2}{*}{ Cuantiles } & \multicolumn{3}{|c|}{ Logaritmo del gasto monetario } & \multicolumn{3}{|c|}{$\begin{array}{l}\text { Logaritmo del gasto en } \\
\text { alimentos }\end{array}$} & \multicolumn{3}{|c|}{$\begin{array}{c}\text { Logaritmo del gasto en bienes } \\
\text { durables }\end{array}$} \\
\hline & 0,25 & $\mathbf{0 , 5 0}$ & 0,75 & 0,25 & 0,50 & 0,75 & 0,25 & 0,50 & 0,75 \\
\hline Tenencia de tarjeta de crédito & $\begin{array}{c}0,013 * * * \\
(11,67)\end{array}$ & $\begin{array}{c}0,025^{* * *} \\
(11,54)\end{array}$ & $\begin{array}{c}0,073 * * * \\
(43,79)\end{array}$ & $\begin{array}{l}-0,004 \\
-(0,62)\end{array}$ & $\begin{array}{l}-0,009^{*} \\
-(1,71)\end{array}$ & $\begin{array}{l}-0,008 \\
-(1,23)\end{array}$ & $\begin{array}{l}-0,112 \\
-(1,24)\end{array}$ & $\begin{array}{l}-0,055 \\
-(1,02)\end{array}$ & $\begin{array}{l}0,009 \\
(0,23)\end{array}$ \\
\hline Logaritmo del ingreso corriente & $\begin{array}{c}0,057^{* * *} \\
(41,67)\end{array}$ & $\begin{array}{c}0,044^{* * *} \\
(57,06)\end{array}$ & $\begin{array}{c}0,052^{* * *} \\
(90,87)\end{array}$ & $\begin{array}{l}-0,035^{* * *} \\
-(62,06)\end{array}$ & $\begin{array}{l}-0,028^{* * *} \\
-(12,50)\end{array}$ & $\begin{array}{l}-0,015^{* * *} \\
-(9,24)\end{array}$ & $\begin{array}{c}0,744^{* * *} \\
(13,50)\end{array}$ & $\begin{array}{c}0,662^{* * *} \\
(24,59)\end{array}$ & $\begin{array}{c}0,555^{* * *} \\
(28,71)\end{array}$ \\
\hline $\begin{array}{l}\text { Años de educación del jefe de } \\
\text { hogar }\end{array}$ & $\begin{array}{c}0,002^{* * *} \\
(7,82)\end{array}$ & $\begin{array}{c}0,002^{* * *} \\
(24,38)\end{array}$ & $\begin{array}{c}0,003^{* * *} \\
(24,24)\end{array}$ & $\begin{array}{l}-0,005^{* * *} \\
-(4,21)\end{array}$ & $\begin{array}{c}-0,004^{* * *} \\
-(8,42)\end{array}$ & $\begin{array}{c}-0,003^{* * *} \\
-(6,58)\end{array}$ & $\begin{array}{l}-0,000 \\
-(0,02)\end{array}$ & $\begin{array}{c}0,020^{* * *} \\
(6,42)\end{array}$ & $\begin{array}{c}0,015^{* * *} \\
(3,24)\end{array}$ \\
\hline Edad del jefe de hogar & $\begin{array}{c}0,002^{* * *} \\
(10,26)\end{array}$ & $\begin{array}{c}0,001^{* * *} \\
(5,03)\end{array}$ & $\begin{array}{c}0,001^{* *} \\
(2,90)\end{array}$ & $\begin{array}{c}0,009^{* * *} \\
(8,04)\end{array}$ & $\begin{array}{c}0,006^{* * *} \\
(7,77)\end{array}$ & $\begin{array}{c}0,004^{* * *} \\
(4,91)\end{array}$ & $\begin{array}{c}0,029 * * \\
(2,62)\end{array}$ & $\begin{array}{c}0,041^{* * *} \\
(4,36)\end{array}$ & $\begin{array}{l}0,015 \\
(1,04)\end{array}$ \\
\hline Edad al cuadrado & $\begin{array}{c}-0,000^{* * *} \\
-(12,98)\end{array}$ & $\begin{array}{l}-0,000^{* * *} \\
-(8,42)\end{array}$ & $\begin{array}{c}-0,000^{* * *} \\
-(3,18)\end{array}$ & $\begin{array}{l}-0,000^{* * *} \\
-(8,88)\end{array}$ & $\begin{array}{c}-0,000^{* * *} \\
-(7,08)\end{array}$ & $\begin{array}{c}-0,000^{* * *} \\
-(3,74)\end{array}$ & $\begin{array}{c}-0,001^{* * *} \\
-(4,94)\end{array}$ & $\begin{array}{c}-0,001^{* * *} \\
-(6,56)\end{array}$ & $\begin{array}{l}-0,000^{*} \\
-(1,78)\end{array}$ \\
\hline Número de integrantes del hogar & $\begin{array}{c}0,006^{* * *} \\
(15,50)\end{array}$ & $\begin{array}{c}0,003^{* * *} \\
(10,44)\end{array}$ & $\begin{array}{l}0,000 \\
(0,08)\end{array}$ & $\begin{array}{c}0,032^{* * *} \\
(8,25)\end{array}$ & $\begin{array}{c}0,017^{* * *} \\
(8,42)\end{array}$ & $\begin{array}{c}0,007^{* * *} \\
(6,47)\end{array}$ & $\begin{array}{c}-0,138^{* * *} \\
-(7,50)\end{array}$ & $\begin{array}{c}-0,118^{* * *} \\
-(17,43)\end{array}$ & $\begin{array}{l}-0,119^{* * *} \\
-(6,61)\end{array}$ \\
\hline Menores de 12 años en el hogar & $\begin{array}{l}-0,001 \\
-(1,46)\end{array}$ & $\begin{array}{l}-0,001 \\
-(1,49)\end{array}$ & $\begin{array}{l}-0,000 \\
-(0,63)\end{array}$ & $\begin{array}{l}0,001 \\
(0,41)\end{array}$ & $\begin{array}{l}0,005 \\
(1,27)\end{array}$ & $\begin{array}{c}0,004^{* * *} \\
(3,34)\end{array}$ & $\begin{array}{l}0,136^{*} \\
(1,94)\end{array}$ & $\begin{array}{c}0,091^{* * *} \\
(3,78)\end{array}$ & $\begin{array}{c}0,086^{* * *} \\
(2,95)\end{array}$ \\
\hline Constante & $\begin{array}{l}7,918^{* * *} \\
(564,21)\end{array}$ & $\begin{array}{l}8,202^{* * *} \\
(839,53)\end{array}$ & $\begin{array}{l}8,219^{* * *} \\
(631,29)\end{array}$ & $\begin{array}{l}7,660^{* * *} \\
(258,96)\end{array}$ & $\begin{array}{l}8,047^{* * *} \\
(295,15)\end{array}$ & $\begin{array}{l}8,236^{* * *} \\
(708,77)\end{array}$ & $\begin{array}{l}-0,231 \\
-(0,36)\end{array}$ & $\begin{array}{c}0,772^{* *} \\
(2,37)\end{array}$ & $\begin{array}{c}2,438^{* * *} \\
(8,06)\end{array}$ \\
\hline $\begin{array}{c}\text { Observaciones } \\
\text { Pseudo R-cuadrado }\end{array}$ & $\begin{array}{l}70.311 \\
0,7322\end{array}$ & $\begin{array}{l}70.311 \\
0,7608\end{array}$ & $\begin{array}{l}70.311 \\
0,7591\end{array}$ & $\begin{array}{l}69.866 \\
0,3356\end{array}$ & $\begin{array}{l}69.866 \\
0,3712\end{array}$ & $\begin{array}{l}69.866 \\
0,4109\end{array}$ & $\begin{array}{l}14.885 \\
0,1054\end{array}$ & $\begin{array}{l}14.885 \\
0,1366\end{array}$ & $\begin{array}{l}14.885 \\
0,1474\end{array}$ \\
\hline \multirow{2}{*}{ Cuantiles } & \multicolumn{3}{|c|}{$\begin{array}{l}\text { Logaritmo del gasto en } \\
\text { educación }\end{array}$} & \multicolumn{3}{|c|}{ Logaritmo del gasto en salud } & \multicolumn{3}{|c|}{$\begin{array}{l}\text { Logaritmo del gasto en otros } \\
\text { bienes no básicos }\end{array}$} \\
\hline & 0,25 & $\mathbf{0 , 5 0}$ & 0,75 & 0,25 & 0,50 & 0,75 & 0,25 & 0,50 & 0,75 \\
\hline Tenencia de tarjeta de crédito & $\begin{array}{l}-0,114^{* *} \\
-(2,23)\end{array}$ & $\begin{array}{l}-0,086^{* *} \\
-(2,47)\end{array}$ & $\begin{array}{l}-0,041^{*} \\
-(1,94)\end{array}$ & $\begin{array}{c}0,142^{* * *} \\
(3,21)\end{array}$ & $\begin{array}{c}0,146^{* * *} \\
(4,70)\end{array}$ & $\begin{array}{c}0,150^{* * *} \\
(8,74)\end{array}$ & $\begin{array}{c}0,039 * * * \\
(4,02)\end{array}$ & $\begin{array}{c}0,046^{* * *} \\
(5,15)\end{array}$ & $\begin{array}{c}0,056^{* * *} \\
(15,72)\end{array}$ \\
\hline Logaritmo del ingreso corriente & $\begin{array}{l}-0,008 \\
-(0,62)\end{array}$ & $\begin{array}{l}-0,021^{*} \\
-(1,86)\end{array}$ & $\begin{array}{c}0,023^{* *} \\
(2,00)\end{array}$ & $\begin{array}{c}0,315^{* * *} \\
(11,33)\end{array}$ & $\begin{array}{c}0,290^{* * *} \\
(30,42)\end{array}$ & $\begin{array}{c}0,252^{* * *} \\
(16,82)\end{array}$ & $\begin{array}{l}0,278^{* * *} \\
(43,70)\end{array}$ & $\begin{array}{c}0,252^{* * *} \\
(76,31)\end{array}$ & $\begin{array}{c}0,238^{* * *} \\
(71,20)\end{array}$ \\
\hline $\begin{array}{l}\text { Años de educación del jefe de } \\
\text { hogar }\end{array}$ & $\begin{array}{c}0,019^{* * *} \\
(8,65)\end{array}$ & $\begin{array}{c}0,022^{* * *} \\
(7,36)\end{array}$ & $\begin{array}{c}0,021^{* * *} \\
(7,30)\end{array}$ & $\begin{array}{c}0,006^{* *} \\
(2,54)\end{array}$ & $\begin{array}{c}0,011^{* * *} \\
(22,43)\end{array}$ & $\begin{array}{c}0,004^{* *} \\
(2,60)\end{array}$ & $\begin{array}{c}0,014^{* * *} \\
(19,65)\end{array}$ & $\begin{array}{c}0,012^{* * *} \\
(54,60)\end{array}$ & $\begin{array}{c}0,011^{* * *} \\
(30,41)\end{array}$ \\
\hline Edad del jefe de hogar & $\begin{array}{c}0,011^{* *} \\
(2,73)\end{array}$ & $\begin{array}{c}0,013^{* * *} \\
(5,49)\end{array}$ & $\begin{array}{c}0,014^{* * *} \\
(7,43)\end{array}$ & $\begin{array}{l}-0,026^{* * *} \\
-(8,94)\end{array}$ & $\begin{array}{l}-0,022^{* * *} \\
-(11,48)\end{array}$ & $\begin{array}{c}-0,013^{* * *} \\
-(4,51)\end{array}$ & $\begin{array}{l}0,002^{*} \\
(1,95)\end{array}$ & $\begin{array}{c}0,003^{* * *} \\
(4,84)\end{array}$ & $\begin{array}{c}0,003^{* * *} \\
(3,53)\end{array}$ \\
\hline Edad al cuadrado & $\begin{array}{l}-0,000^{* *} \\
-(2,34)\end{array}$ & $\begin{array}{c}-0,000^{* * *} \\
-(4,47)\end{array}$ & $\begin{array}{c}-0,000^{* * *} \\
-(5,89)\end{array}$ & $\begin{array}{c}0,000^{* * *} \\
(21,56)\end{array}$ & $\begin{array}{c}0,000^{* * *} \\
(24,40)\end{array}$ & $\begin{array}{c}0,000^{* * *} \\
(11,21)\end{array}$ & $\begin{array}{c}-0,000^{* * *} \\
-(3,79)\end{array}$ & $\begin{array}{c}-0,000^{* * *} \\
-(6,53)\end{array}$ & $\begin{array}{c}-0,000^{* * *} \\
-(3,48)\end{array}$ \\
\hline Número de integrantes del hogar & $\begin{array}{c}0,037^{* * *} \\
(6,52)\end{array}$ & $\begin{array}{c}0,035^{* * *} \\
(7,25)\end{array}$ & $\begin{array}{c}0,046^{* * *} \\
(14,15)\end{array}$ & $\begin{array}{l}-0,093^{* * *} \\
-(24,39)\end{array}$ & $\begin{array}{l}-0,101^{* * *} \\
-(23,87)\end{array}$ & $\begin{array}{c}-0,109^{* * *} \\
-(22,28)\end{array}$ & $\begin{array}{c}0,003^{* * *} \\
(5,26)\end{array}$ & $\begin{array}{c}-0,009^{* * *} \\
-(5,44)\end{array}$ & $\begin{array}{c}-0,018^{* * *} \\
-(9,66)\end{array}$ \\
\hline Menores de 12 años en el hogar & $\begin{array}{c}-0,069^{* * *} \\
-(5,59)\end{array}$ & $\begin{array}{c}-0,082^{* * *} \\
-(10,04)\end{array}$ & $\begin{array}{l}-0,092^{* * *} \\
-(34,05)\end{array}$ & $\begin{array}{c}0,122^{* * *} \\
(6,93)\end{array}$ & $\begin{array}{c}0,077^{* *} \\
(6,69)\end{array}$ & $\begin{array}{c}0,048^{* * *} \\
(7,43)\end{array}$ & $\begin{array}{c}-0,019^{* * *} \\
-(7,17)\end{array}$ & $\begin{array}{c}-0,018^{* * *} \\
-(10,31)\end{array}$ & $\begin{array}{c}-0,017^{* * *} \\
-(6,62)\end{array}$ \\
\hline Constante & $\begin{array}{c}5,281^{* * *} \\
(34,58)\end{array}$ & $\begin{array}{c}6,036^{* * *} \\
(60,69)\end{array}$ & $\begin{array}{c}6,199^{* * *} \\
(89,39)\end{array}$ & $\begin{array}{c}0,935^{* * *} \\
(3,97)\end{array}$ & $\begin{array}{c}2,085^{* * *} \\
(21,68)\end{array}$ & $\begin{array}{c}3,182^{* * *} \\
(17,36)\end{array}$ & $\begin{array}{c}4,852^{* * *} \\
(75,55)\end{array}$ & $\begin{array}{l}5,430^{* * *} \\
(170,69)\end{array}$ & $\begin{array}{l}5,882^{* * *} \\
(164,14)\end{array}$ \\
\hline $\begin{array}{c}\text { Observaciones } \\
\text { Pseudo R-cuadrado }\end{array}$ & $\begin{array}{l}31.000 \\
0,1317\end{array}$ & $\begin{array}{l}31.000 \\
0,1831\end{array}$ & $\begin{array}{l}31.000 \\
0,2330\end{array}$ & $\begin{array}{l}37.447 \\
0,0755\end{array}$ & $\begin{array}{l}37.447 \\
0,0913\end{array}$ & $\begin{array}{l}37.447 \\
0,1176\end{array}$ & $\begin{array}{l}70.214 \\
0,5364\end{array}$ & $\begin{array}{l}70.214 \\
0,5471\end{array}$ & $\begin{array}{l}70.214 \\
0,5557\end{array}$ \\
\hline
\end{tabular}

*** $1 \%,{ }^{* *} 5 \%$ y $10 \%$ de significancia; en paréntesis se encuentran los estadísticos $t$; errores estándar calculados por Bootstrap 250 reps; todas las estimaciones se controlan por sexo del jefe de hogar, localización urbana/rural y nivel socioeconómico, como se propuso en la tabla 2 .

Fuente: elaboración propia con datos de la ENIGH 2016. 
Figura 2.

Coeficientes de las TC por rubro y cuantil de gasto

a) Total monetario

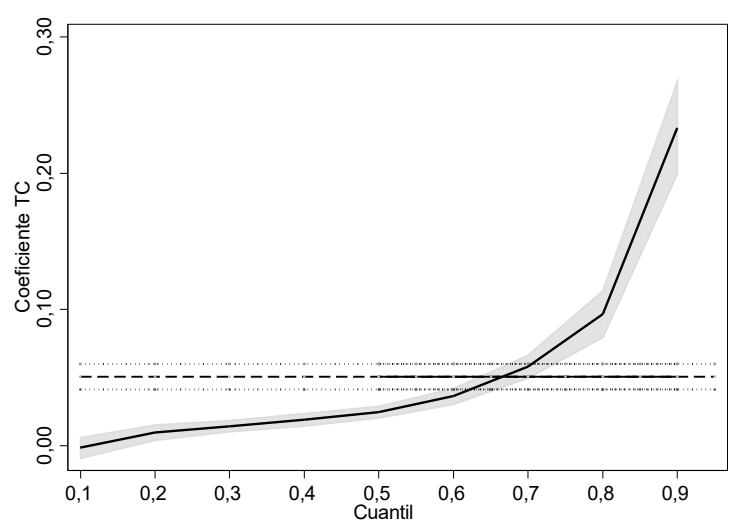

c) Bienes durables

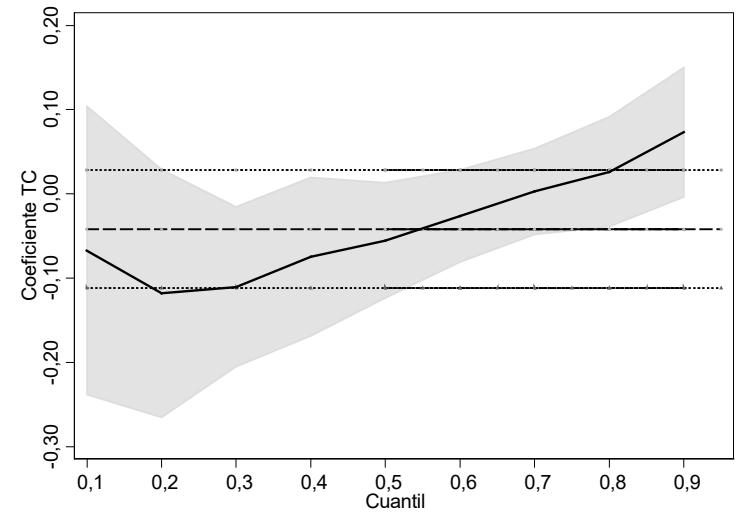

e) Salud

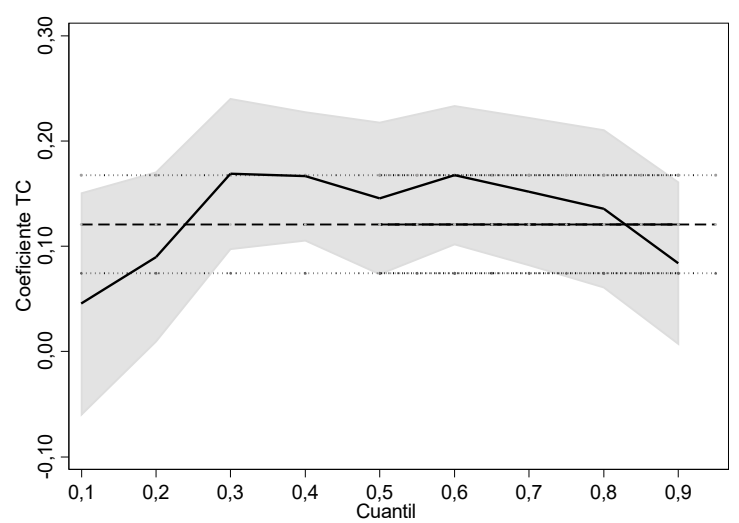

b) Alimentos

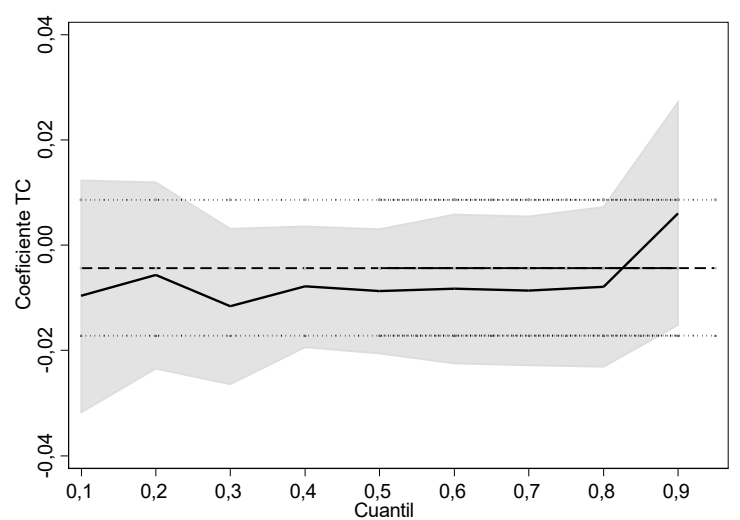

d) Educación

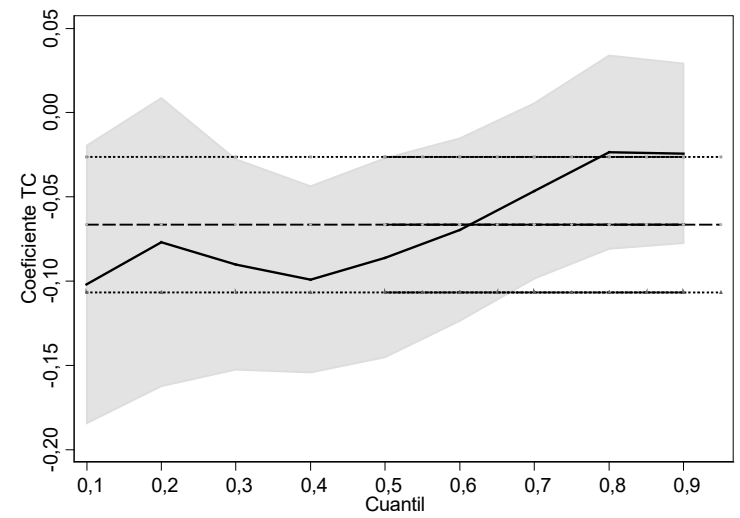

f) Otros bienes no básicos

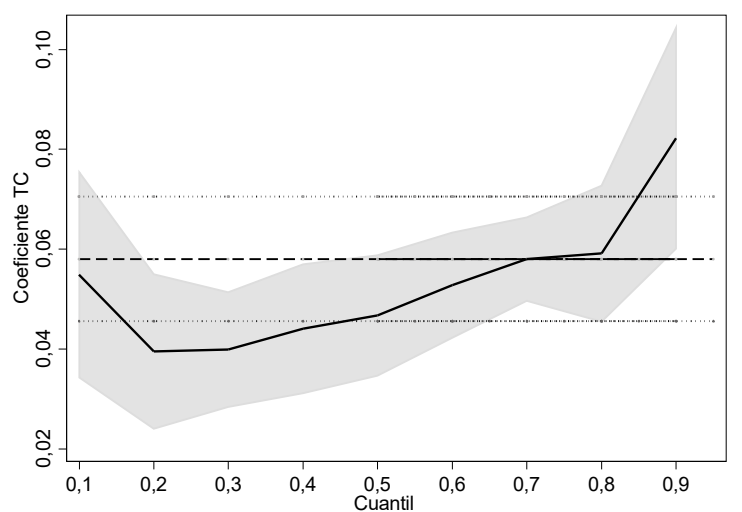

Nota: las líneas horizontales (guiones y punteadas) en cada gráfica muestran la estimación MCO y su intervalo de confianza; las líneas sólidas y las áreas en gris representan los coeficientes y los intervalos al 95\% de confianza de cada regresión cuantílica.

Fuente: elaboración propia con datos de la ENIGH 2016. 
efectos positivos estadísticamente y significativos de la tenencia del servicio financiero. En el caso del gasto en bienes durables los efectos son muy pequeños, al punto de no ser significativos, y en el gasto en educación los efectos son negativos. El gasto en salud presenta efectos positivos, pero son los deciles centrales los que más se benefician de la tenencia de TC.

\section{INSTRUMENTACIÓN DE LA TENENCIA DE TARJETAS DE CRÉDITO EN LA ESTRUCTURA Y DISTRIBUCIÓN DEL GASTO}

En la revisión de determinantes por cuantiles hay un primer indicio de efectos positivos de las TC sobre el total de consumo, pero el análisis por categorías mostró que los impactos son diferenciados dependiendo del rubro de gasto. En este apartado se usa un conjunto de variables instrumentales para depurar los efectos y corregir el sesgo que proviene de la autoselección en el uso del servicio financiero (Vella, 1998). Con este objetivo, se hace una breve descripción de la estrategia metodológica, se justifican los instrumentos seleccionados y se presentan, en dos etapas, los resultados de estimaciones de mínimos cuadrados (VI-MC2E) y regresión cuantílica.

El problema de identificación que se enfrenta al estimar los efectos de las TC sobre el consumo es que, dadas las características de los hogares, el uso de este servicio financiero es una decisión endógena. Imagínese que familias con buenas expectativas sobre sus flujos de ingreso deciden tener TC; dichas expectativas no son directamente observables y a su vez generan cambios en el consumo; en este caso, la variable explicativa no cumple con el supuesto de exogeneidad necesario para estimar por MCO el modelo lineal clásico.

Como sugiere Angrist (2001), una solución a este problema es el uso de variables instrumentales para estimar el efecto causal de la variable explicativa. El reto es encontrar un conjunto de variables que sean buenas explicando la tenencia de TC (primera etapa del modelo), pero que no afecten de forma directa el consumo de los hogares (segunda etapa).
Villarreal (2014) sugiere que la tenencia y uso de TC se asocia con las posibilidades de acceso físico, los conocimientos financieros y algunos aspectos demográficos. En este ejercicio se usan como instrumentos de las TC el tamaño de localidad, una variable dicotómica del nivel de educación, el número de adultos mayores en el hogar y el acceso a internet. En localidades más grandes con mayor infraestructura bancaria existe mayor acceso físico al servicio de TC. La variable del nivel de educación representa un umbral mínimo de capital humano vinculado a algunos conocimientos financieros básicos; el número de adultos mayores en el hogar representa la afinidad demográfica de la familia con los servicios financieros; el acceso a internet muestra la cercanía a la innovación y el acceso a servicios del hogar.

\section{Efectos de las tarjetas de crédito por categoría de gasto}

La tabla 4 presenta estimaciones de los rubros de consumo por MCO y la segunda etapa del modelo una vez se instrumenta la tenencia de TC (VI-MC2E). En los seis modelos por variables instrumentales se hicieron las pruebas correspondientes; en todos los casos se rechazan las hipótesis de subidentificación (Anderson, 1951), de instrumentos débiles (Cragg-Donald, 1993) y no se rechazan las hipótesis de que los instrumentos son válidos y fueron bien excluidos de las ecuaciones principales (prueba de sobreidentificación Sargan-Hansen).

Después de corregir el problema de autoselección, los resultados confirman los efectos positivos de las TC sobre el total del gasto monetario. El modelo VI-MC2E indica efectos de alrededor de 28 puntos porcentuales de la tenencia de TC sobre el total de consumo, y tal como se anticipó en las regresiones cuantílicas, dicho efecto es conducido por los gastos en otros bienes y los gastos en salud (efectos positivos de 23,6 y cerca de 300 puntos porcentuales, respectivamente). Más importante es que las estimaciones sugieren que no hay efectos significativos de las TC sobre gastos como la educación y el gasto en bienes durables; 


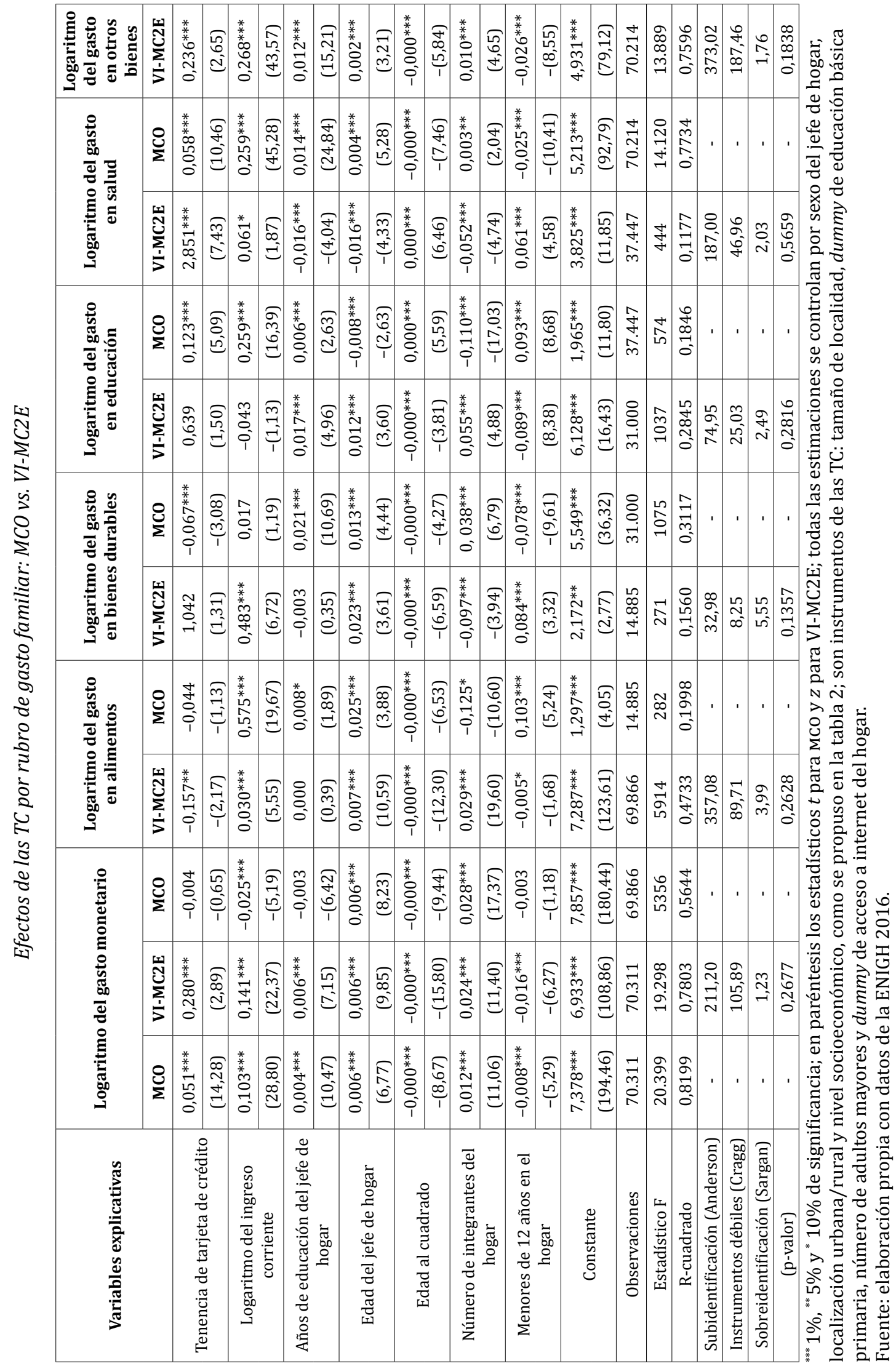


mientras tanto, los efectos en los alimentos son incluso negativos. A excepción del gasto en salud, los resultados permiten cuestionar los efectos de las TC sobre la acumulación de capital humano y el bienestar futuro representados en la inversión en educación y la acumulación de bienes durables en el hogar.

\section{Efectos de las TC en la distribución de gasto: regresión cuantílica en dos etapas}

En esta sección se realizan regresiones cuantílicas en dos etapas para observar cómo se distribuyen los efectos en los rubros de gasto cuando se corrige el problema de autoselección de las TC. Al igual que en la primera etapa de los modelos del apartado anterior, se instrumenta la tenencia de TC con una variable del tamaño de localidad, una dummy de educación básica primaria del jefe de familia, el número de adultos mayores en el hogar y una dummy de acceso a internet; pero en lugar de estimar la segunda etapa por MCO, esto se hace por medio de regresiones cuantílicas de cada rubro de gasto.

En la tabla 5 y la figura 3 se presentan los efectos de las TC como resultado de las regresiones cuantílicas en dos etapas, para los seis rubros de interés, por decil de gasto. En general se confirman los efectos positivos de las TC sobre el gasto monetario

Tabla 5.

Efectos de las TC por rubro y cuantiles de gasto: regresión cuantílica en dos etapas

\begin{tabular}{|c|c|c|c|c|c|c|c|c|c|}
\hline \multirow{2}{*}{ Rubro } & \multicolumn{9}{|c|}{ Cuantiles } \\
\hline & $\mathbf{0 , 1 0}$ & 0,20 & $\mathbf{0 , 3 0}$ & $\mathbf{0 , 4 0}$ & 0,50 & 0,60 & 0,70 & 0,80 & 0,90 \\
\hline \multirow{2}{*}{$\begin{array}{l}\text { Logaritmo del gasto } \\
\text { monetario }\end{array}$} & $-0,357^{* * *}$ & $-0,084$ & $0,173^{* * *}$ & $0,362^{* * *}$ & $0,426^{* * *}$ & $0,492^{* * *}$ & $0,634^{* * *}$ & $0,843^{* * *}$ & $1,677^{* * *}$ \\
\hline & $-(4,01)$ & $-(0,92)$ & $(3,68)$ & $(7,21)$ & $(15,80)$ & $(28,13)$ & $(14,06)$ & $(17,58)$ & $(13,18)$ \\
\hline Observaciones & 70.311 & 70.311 & 70.311 & 70.311 & 70.311 & 70.311 & 70.311 & 70.311 & 70.311 \\
\hline Pseudo R-cuadrado & 0,6165 & 0,6513 & 0,6687 & 0,6780 & 0,6833 & 0,6859 & 0,6861 & 0,6828 & 0,6730 \\
\hline \multirow{2}{*}{$\begin{array}{l}\text { Logaritmo del gasto en } \\
\text { alimentos }\end{array}$} & $-0,825^{* * *}$ & $-0,553^{* * *}$ & $-0,264^{* * *}$ & $-0,179^{* * *}$ & $-0,066^{* *}$ & $-0,008$ & $0,138^{* * *}$ & $0,273^{* * *}$ & $0,478^{* * *}$ \\
\hline & $-(12,68)$ & $-(4,32)$ & $-(9,18)$ & $-(4,78)$ & $-(2,21)$ & $-(0,31)$ & $(4,10)$ & $(4,15)$ & $(11,48)$ \\
\hline Observaciones & 69.866 & 69.866 & 69.866 & 69.866 & 69.866 & 69.866 & 69.866 & 69.866 & 69.866 \\
\hline Pseudo R-cuadrado & 0,2893 & 0,3075 & 0,3223 & 0,3350 & 0,3472 & 0,3602 & 0,3740 & 0,3905 & 0,4106 \\
\hline \multirow{2}{*}{$\begin{array}{l}\text { Logaritmo del gasto en } \\
\text { bienes durables }\end{array}$} & 2,043 & $3,646^{* *}$ & $2,485^{* *}$ & 1,331 & 0,908 & 0,180 & 0,017 & $-0,707$ & $-0,348$ \\
\hline & $(1,42)$ & $(1,87)$ & $(1,99)$ & $(1,57)$ & $(1,35)$ & $(0,35)$ & $(0,05)$ & $-(1,10)$ & $-(0,57)$ \\
\hline Observaciones & 14.885 & 14.885 & 14.885 & 14.885 & 14.885 & 14.885 & 14.885 & 14.885 & 14.885 \\
\hline Pseudo R-cuadrado & 0,0531 & 0,0855 & 0,1233 & 0,1392 & 0,1368 & 0,1373 & 0,1430 & 0,1555 & 0,1811 \\
\hline \multirow{2}{*}{$\begin{array}{c}\text { Logaritmo del gasto en } \\
\text { educación }\end{array}$} & 0,452 & $-0,990$ & 0,106 & 0,218 & 0,646 & 0,601 & $0,838^{* *}$ & $1,126^{* *}$ & $0,946^{* *}$ \\
\hline & $(0,51)$ & $-(1,33)$ & $(0,19)$ & $(0,41)$ & $(1,43)$ & $(1,43)$ & $(2,14)$ & $(3,10)$ & $(2,13)$ \\
\hline Observaciones & 31.000 & 31.000 & 31.000 & 31.000 & 31.000 & 31.000 & 31.000 & 31.000 & 31.000 \\
\hline Pseudo R-cuadrado & 0,1011 & 0,1207 & 0,1423 & 0,1627 & 0,1829 & 0,2025 & 0,2224 & 0,2445 & 0,2738 \\
\hline \multirow{2}{*}{$\begin{array}{c}\text { Logaritmo del gasto en } \\
\text { salud }\end{array}$} & $3,410^{* * *}$ & $3,153^{* * *}$ & $2,899 * * *$ & $3,169^{* * *}$ & $3,106^{* * *}$ & $3,200^{* * *}$ & $3,308^{* * *}$ & $3,386^{* * *}$ & $2,477^{* * *}$ \\
\hline & $(4,70)$ & $(6,13)$ & $(4,08)$ & $(6,52)$ & $(5,44)$ & $(5,14)$ & $(4,64)$ & $(7,15)$ & $(3,72)$ \\
\hline Observaciones & 37.447 & 37.447 & 37.447 & 37.447 & 37.447 & 37.447 & 37.447 & 37.447 & 37.447 \\
\hline Pseudo R-cuadrado & 0,0663 & 0,0754 & 0,0803 & 0,0856 & 0,0947 & 0,1037 & 0,1153 & 0,1273 & 0,1446 \\
\hline \multirow{2}{*}{$\begin{array}{l}\text { Logaritmo del gasto en } \\
\text { otros bienes no básicos }\end{array}$} & $-0,162$ & $-0,123$ & $-0,075$ & 0,082 & $0,229 * *$ & $0,338^{* * *}$ & $0,470 * * *$ & $0,742^{* * *}$ & $1,207^{* * *}$ \\
\hline & $-(0,98)$ & $-(1,05)$ & $-(0,67)$ & $(0,86)$ & $(2,45)$ & $(3,68)$ & $(5,11)$ & $(7,21)$ & $(8,71)$ \\
\hline Observaciones & 70.214 & 70.214 & 70.214 & 70.214 & 70.214 & 70.214 & 70.214 & 70.214 & 70.214 \\
\hline Pseudo R-cuadrado & 0,5205 & 0,5249 & 0,5278 & 0,5303 & 0,5325 & 0,5346 & 0,5362 & 0,5373 & 0,5364 \\
\hline
\end{tabular}

${ }^{* * *} 1 \%,{ }^{* *} 5 \%$ y ${ }^{*} 10 \%$ de significancia; en paréntesis se presentan los estadísticos $t$; errores estándar calculados por Bootstrap 250 reps; to-das las estimaciones se controlan por el logaritmo del ingreso, edad y edad al cuadrado, años de escolaridad y sexo del jefe de hogar, número de integrantes y de menores de 12 años en el hogar, localización urbana/ rural y nivel socioeconómico, como se propuso en la tabla 2.

Fuente: elaboración propia con datos de la ENIGH 2016. 
Figura 3.

Efectos de las TC por rubro y cuantil de gasto

a) Total monetario

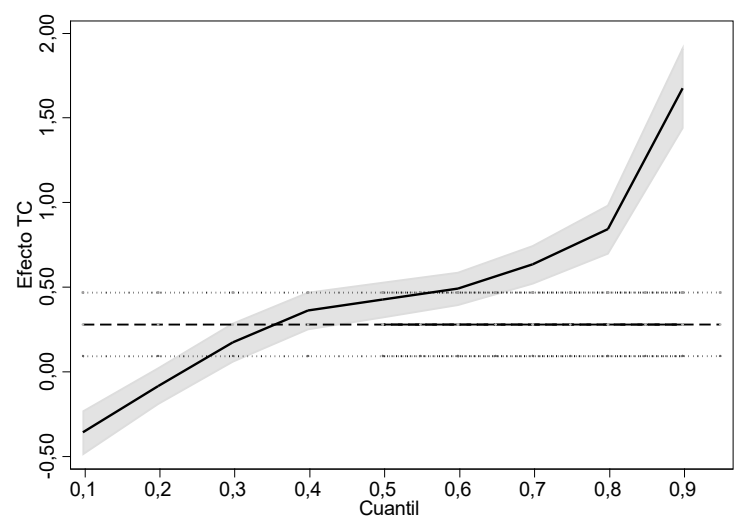

c) Bienes durables

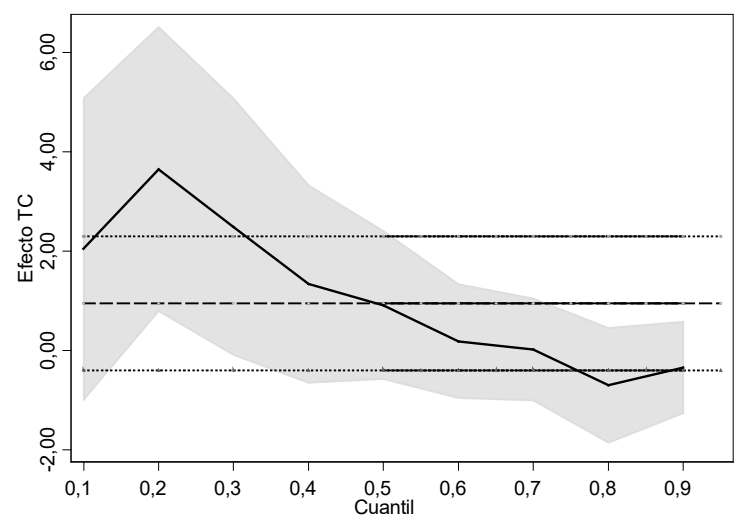

e) Salud

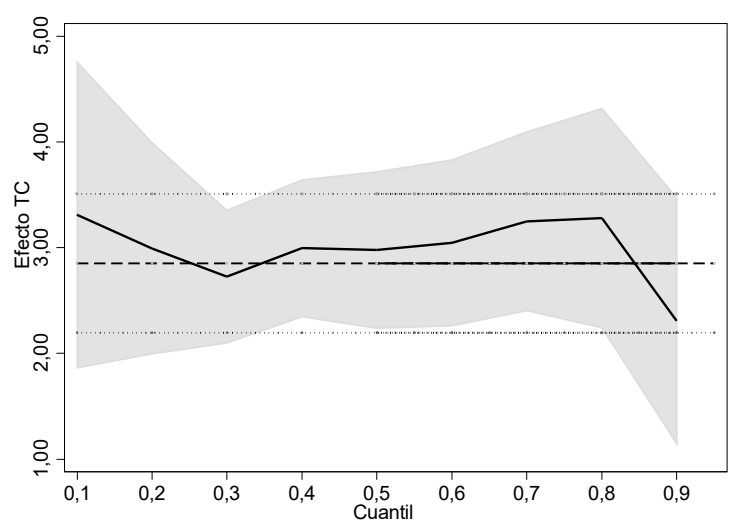

b) Alimentos

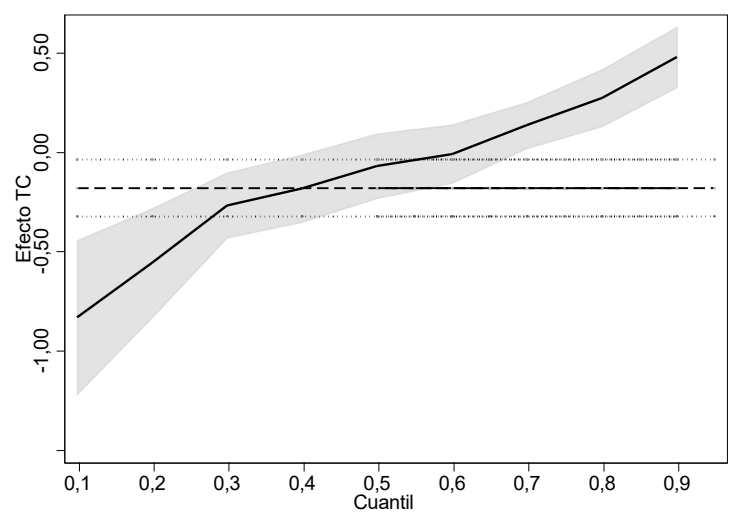

d) Educación

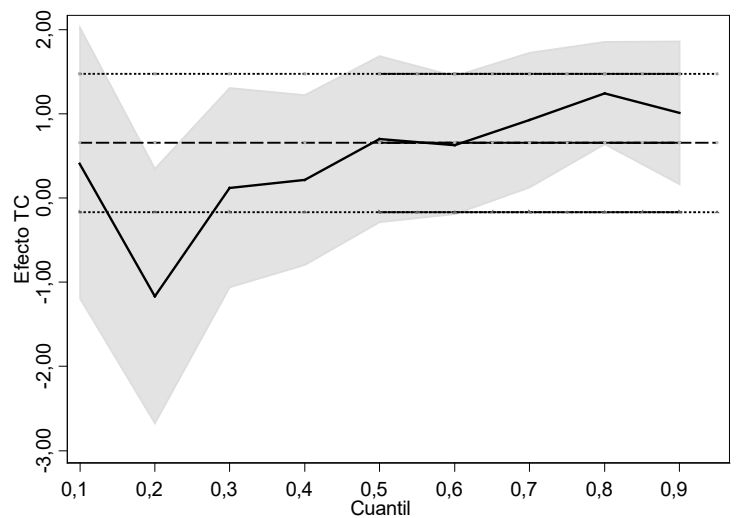

f) Otros bienes no básicos

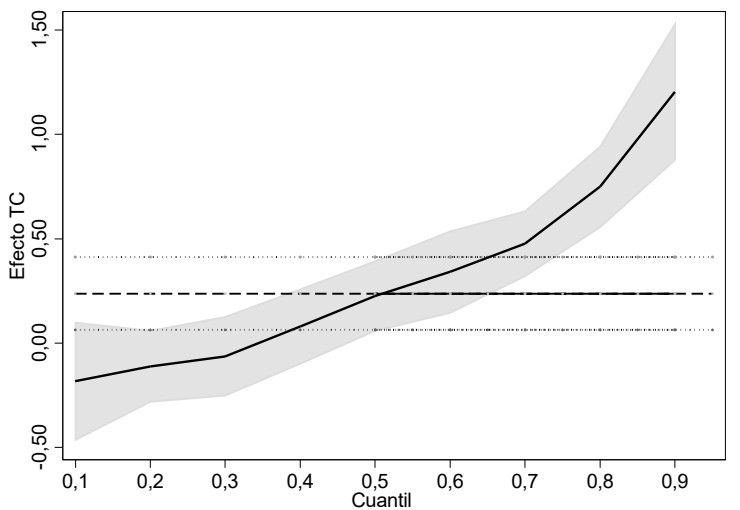

Nota: las líneas horizontales (guiones y punteadas) en cada gráfica muestran la estimación MCO y su intervalo de confianza; las líneas sólidas y las áreas en gris representan los coeficientes y los intervalos al 95\% de confianza de cada regresión cuantílica.

Fuente: elaboración propia con datos de la ENIGH 2016. 
con un comportamiento creciente a lo largo de la distribución. El efecto en el noveno decil es cerca de 10 veces el de las TC sobre el tercer decil de gasto monetario; en el segundo decil no hay efectos significativos, mientras en el primer decil el efecto de las TC sobre el total de gasto monetario es incluso negativo. La tenencia de TC disminuye el gasto en alimentos del primer al quinto decil, mientras tiene efectos positivos de 14 y hasta 48 puntos porcentuales a partir del séptimo y hasta el noveno decil, mostrando efectos crecientes a lo largo de la distribución, al igual que el gasto monetario y el gasto en bienes durables.

En cuanto a los efectos de las TC sobre el gasto en bienes durables, solo se identifican efectos significativos y positivos en el segundo y tercer decil; en el resto de la distribución se confirma la ausencia de efectos estadísticos, tal como se predijo en la media con los modelos de variables instrumentales. Asimismo, el gasto en educación solo reporta efectos positivos de la tenencia de TC en la parte alta de la distribución a partir del séptimo decil, mientras que del sexto decil hacia la parte baja no existen efectos estadísticos. A diferencia de lo que ocurre con estos gastos, en el caso de la salud las TC tienen efectos grandes y significativos a lo largo de toda la distribución, al presentar un comportamiento estable alrededor del efecto predicho por el modelo VI-MC2E. Finalmente, en el caso de los otros bienes (vestido, transporte, comunicaciones, entre otros), los efectos de las TC son altos y significativos en la parte alta de la distribución, al mostrar un comportamiento creciente.

\section{INCLUSIÓN FINANCIERA EN MÉXICO Y DESIGUALDAD}

En este apartado se hace una reflexión sobre la política de inclusión financiera del país y sus necesidades más inmediatas para lograr los objetivos de bienestar y el cierre de brechas económicas en la población. Se inicia con una propuesta esquemática de los elementos que intervienen en el proceso de inclusión financiera; luego se identifican la debilidad de los determinantes del lado de la demanda y la imposibilidad de llevar a buen término el proceso de inclusión en las condiciones actuales; finalmente, se hacen algunas propuestas y recomendaciones asociadas con el fortalecimiento de las capacidades y de la cultura financiera para equilibrar la demanda de servicios con el nivel de la oferta del actual proceso de inclusión promovido en el país.

\section{Determinantes del proceso de inclusión financiera}

Las estrategias de inclusión financiera en Latinoamérica han tomado gran relevancia con la expectativa de extraer los beneficios derivados del proceso de desarrollo financiero y distribuirlos entre la población más necesitada (Alonso et al., 2014; Villarreal, 2014; Demirgüç-Kunt y Klapper, 2012; Beck, Demirgüç-Kunt y Levine, 2007); sin embargo, antes de acceder a dichos beneficios, se debe identificar cuáles son los elementos y mecanismos que intervienen en un adecuado proceso de inclusión. La literatura internacional ha definido la inclusión financiera como el proceso de promover el adecuado y oportuno acceso a productos y servicios financieros regulados para contribuir al bienestar económico y a la inclusión de todos los segmentos de la población (OCDE, 2015).

Esta literatura ha hecho mucho énfasis en que la inclusión financiera debe fundamentarse en cuatro dimensiones: a) acceso a los servicios, b) uso de los servicios, c) calidad de los servicios y d) bienestar de la población que usa los servicios financieros (Alianza para la Inclusión Financiera [AFI], 2011). Uno de los temas de manifiesto es que el proceso de inclusión financiera y sus dimensiones son una problemática que se desenvuelve en el ámbito del mercado de los servicios financieros. En busca de incorporar todos los elementos necesarios en el proceso de inclusión, la propuesta de este artículo es reconocer que la problemática está determinada por la participación de los elementos de oferta y demanda del mercado de servicios financieros, como se presenta en la figura 4. 
El argumento es que, para promover el acceso, el uso, la calidad y el bienestar derivado de los servicios financieros, del lado de la oferta se necesita garantizar la provisión de los servicios y productos financieros en un ámbito competitivo y regulado. La perspectiva de oferta de los servicios financieros es la más trabajada en el contexto de inclusión del país según la evidencia disponible, pero no basta con centrar el esfuerzo de este lado para llevar a cabo un buen proceso de inclusión. Los elementos del lado de la demanda propuestos en la figura 4 son indispensables para los objetivos deseados; en México los avances en términos de acceso a la tecnología e información, elementos como las capacidades financieras y el alfabetismo financiero presentan un rezago importante (Rodríguez y Dorantes, 2016; Holzmann, Mulaj y Perotti, 2013).

Figura 4.

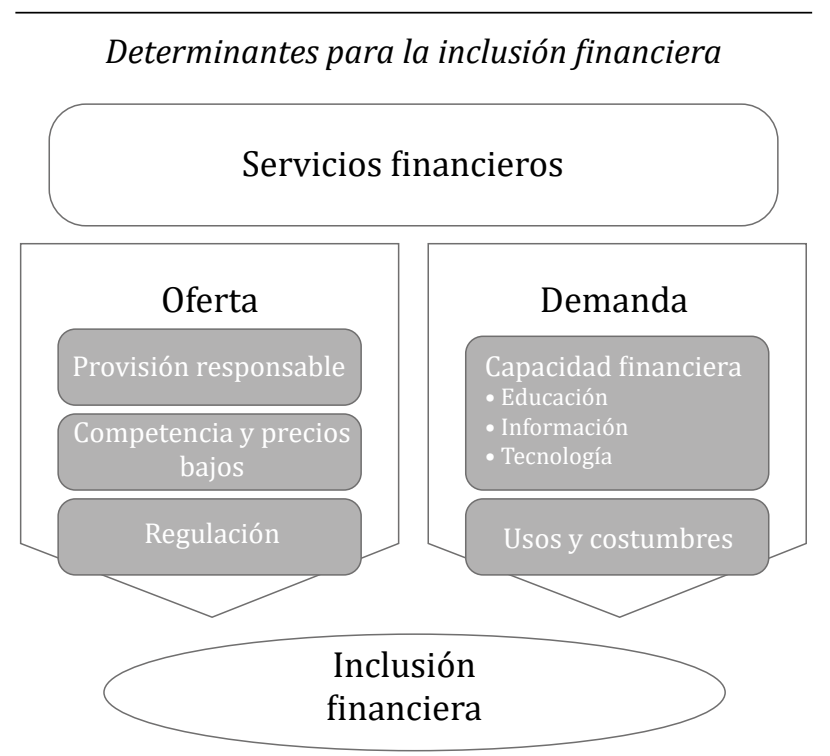

Fuente: elaboración propia.

El proceso de inclusión financiera en el país, desde la perspectiva de política pública, es conducido por una estrategia que concentra sus esfuerzos mediante el Consejo Nacional de Inclusión Financiera (CONAIF) ${ }^{4}$, órgano interinstitucional

$4 \quad$ El CONAIF está integrado por la Secretaría de Hacienda y Crédito Público (SHCP), el Banco de México, el Instituto para la Protección del Ahorro Bancario (IPAB), la Tesorería de la Federación, la Comisión Nacional de Seguros Fianzas (CNSF), la Comisión Nacional para la Protección y Defensa constituido desde el 2011 y cuyo objeto es establecer las condiciones para promover la competencia, la provisión de acceso financiero sostenible, la innovación y la protección del consumidor. Sus objetivos se organizan en el marco de una definición de inclusión financiera no muy lejana a la de la literatura internacional, pero resalta elementos del lado de demanda como educación y capacidades financieras. En concreto, define inclusión financiera como "aquella que comprende el acceso y uso de servicios financieros bajo una regulación apropiada que garantice esquemas de protección al consumidor y promueva la educación financiera para mejorar las capacidades financieras de todos los segmentos de la población" (Diario Oficial de la Federación, 2011)

Según la CNBV (2012), el CONAIF se organiza en cuatro frentes de trabajo para dar cumplimiento a sus objetivos: a) medición, diagnóstico y divulgación de la inclusión financiera, b) modelos de negocio para promover la inclusión, c) protección al consumidory d) educación financiera. Entre el 2012 y el 2015 la ENIF reportó avances en la provisión y acceso a servicios formales, con un incremento de $56 \%$ a $68 \%$ de la población con algún servicio o producto financiero. En términos de promoción de la competencia y regulación, la reforma del 2013 es un avance, pero, pese al intento por incorporar el tema de las capacidades financieras y de educación, el diagnóstico no tiene muchos avances por reportar desde el ámbito de la creación de una cultura financiera.

La responsabilidad de los elementos del lado de la demanda ha recaído sobre el Comité de Educación Financiera y en la CONDUSEF; en el comité se discute la incorporación de programas de educación financiera en la educación básica obligatoria del país, mientras CONDUSEF implementa estrategias de promoción como la Semana de Educación Financiera, una revista y una página web sobre el tema. A pesar de los esfuerzos, el poco

de Usuarios de los Servicios Financiero (CONDUSEF), la Comisión Nacional Bancaria y de Valores (CNBV) y la Comisión Nacional del Sistema de Ahorro para el Retiro (CONSAR). 
avance hacia la creación de una cultura financiera se refleja en el control de gastos y el manejo de las finanzas personales de la población. De hecho, según la ENIF del 2015, solo el $36 \%$ de la población adulta lleva un registro de sus gastos; más aún, solo alrededor del $10 \%$ de la población total lleva su registro en papel o de forma digital, mientras el $26 \%$ restante - que dice llevar un registro- solo lo hace mentalmente.

Según Ponce, Seira y Zamarripa (2017), en México quienes tienen TC pagan $31 \%$ adicional de su costo mínimo de financiamiento. Además, en los descriptivos de este documento se evidenció que son los quintiles de ingresos más bajos los que pagan más intereses por las compras con sus TC. Sin duda, estos datos son indicativos de que, dada la dinámica de oferta, sectores de la población de menores recursos en reciente contacto con los servicios financieros pagan más en el proceso de inclusión. En este contexto, el insuficiente esfuerzo sobre la construcción de capacidades financieras que soporten la oferta puede contribuir al incremento de las desigualdades.

\section{Propuestas y recomendaciones}

La generación de estrategias para enfrentar la problemática de inclusión financiera y la creación del capital humano para nivelar la oferta y la demanda de servicios financieros debe tener en cuenta que el mercado por sí mismo no posee los mecanismos ni crea los incentivos suficientes para proveer los conocimientos, las capacidades y la cultura financiera necesaria para obtener los beneficios deseados del proceso de inclusión. La responsabilidad de crear los mecanismos e incentivos recae sobre las autoridades y diseñadores de política pública, aunque no se niega la posibilidad de involucrar a las instituciones financieras y el resto de sectores en el proceso de generación de capital humano.

Se deben reconocer los esfuerzos vinculados a la impartición y difusión de la educación financiera; de estos esfuerzos en los que participan la Secretaría de Educación Pública (SEP), el Banco de México, CNBV y CONDUSEF, quizás el logro más importante esté por llegar mediante la incorporación de conocimientos financieros en los niveles de educación básica obligatoria. A pesar del gran paso que representaría implementar esta práctica, es evidente que este es solo un avance en la generación de capacidades y la creación de un buen nivel de cultura financiera en el país. La hipótesis de este ejercicio es que para mejorar los niveles de capital humano en el contexto de inclusión financiera, se necesita una estrategia de cimentación de una cultura que parta de los usos y costumbres en la administración de las finanzas personales.

Los elementos del lado de la demanda para la inclusión financiera mostrados en la figura 1 dan cuenta del incremento de las capacidades financieras por medio de la educación y el acceso a información financiera facilitada por el uso de la tecnología. En este orden de ideas, las capacidades financieras de la población se pueden ver afectadas positivamente por la incorporación de la educación financiera en la educación básica obligatoria y por la gran dinámica del uso de las tecnologías de información en el país ${ }^{5}$; sin embargo, la evidencia empírica sobre el alfabetismo financiero muestra la gran relación del tema financiero con la capacidad de cálculo de la población y el uso de las matemáticas (González y Villagómez, 2014).

Al mismo nivel de la creación de las capacidades en la población, la construcción de una cultura financiera tiene el importante componente de usos y costumbres en el ejercicio día a día de las decisiones económicas. No es poco significativo el bajo porcentaje de población que no se preocupa por la contabilidad de sus gastos personales, siendo este uno de los ejercicios más básicos en las finanzas personales. Las prácticas cotidianas alrededor de las finanzas personales, especialmente en los

$5 \quad$ La Encuesta Nacional sobre la Disponibilidad y Uso de Tecnologías de la Información en los Hogares (ENDUTIH) reporta un incremento de $243 \%$ en el uso de acceso a herramientas tecnológicas entre el 2005 y el 2015. Más aún, casi $70 \%$ de los hogares en el país en el 2015 tenían acceso a un celular, tableta, computadora o dispositivo electrónico con conexión a internet. 
niveles más bajos de la distribución de ingresos y gastos, redundan en sus mayores costos de inclusión financiera; primero por los costos del financiamiento y después por el carácter poco redituable del consumo financiado. En este contexto, la estrategia para la creación de capital humano debería centrarse en mejorar la administración de las finanzas personales, no solo en los más jóvenes, sino como una estrategia masiva que logre involucrar a todos los sectores.

Entre las ideas para esta estrategia de creación de una cultura financiera alrededor de las finanzas personales, más allá de los efectos de la educación financiera en los niveles básicos obligatorios, se podría considerar una propuesta de incentivos fiscales para aquellas empresas que logren programas exitosos de mejora en la administración de las finanzas personales de sus empleados, teniendo como objetivo final el ahorro. Sin duda, el ámbito laboral es uno de los de mayor alcance en el cambio de hábitos, usos y costumbres en la población adulta del país, por lo que resultaría un buen complemento de la estrategia educativa, y lo más importante es que los usos y costumbres bien orientados son generadores y refuerzan las capacidades necesarias del lado de la demanda.

\section{CONCLUSIONES}

Se usaron variables instrumentales y regresiones cuantílicas para mostrar que las TC tienen efectos positivos sobre el total de gasto monetario y efectos diferenciados sobre el gasto en alimentos, pero no tienen efectos significativos en la educación y en el gasto en bienes durables; es decir, a excepción de los efectos sobre la salud -que son altos y constantes a lo largo de la distribución-, se pueden cuestionar los efectos de las TC en varias ramas de la acumulación de capital humano y del bienestar futuro de los hogares. Los efectos de estos servicios financieros se concentran en el consumo de bienes menos básicos como calzado, vestido, transporte, comunicaciones y esparcimiento. También se identificó que los efectos de las
TC son mayores en la parte alta de la distribución de consumo, mientras que las familias de menores recursos pagan más intereses por el uso de estos servicios formales.

Los resultados indican que, pese al dinámico crecimiento del mercado de las TC y su gran penetración como instrumento financiero en los hogares, se debe ser cuidadoso en el análisis como objeto de la política de inclusión financiera del país. Este servicio financiero posee efectos diferenciados, y por ello justamente son los hogares con menos recursos los que ven comprometido su bienestar futuro. Probablemente estos hogares estén cayendo en un sobreendeudamiento asociado con un consumo de bajos retornos (gastar en vestido, calzado, esparcimiento y comunicaciones) y comprometiendo ingresos futuros a altas tasas de interés. La literatura asocia tal comportamiento con una baja cultura y capacidad financiera de los usuarios en términos del conocimiento y uso de estos servicios; es decir, gran parte de la explicación es la ausencia de una adecuada acumulación de capital humano.

Este ejercicio pone de manifiesto los grandes riesgos de la inclusión financiera usando servicios como las TC para la población de menos recursos sin un tratamiento realmente focalizado para el segmento. Es probable que la población de ingresos bajos tienda a percibir las TC como un incremento de su riqueza; esta población puede pensar que tiene dinero adicional, comprar impulsivamente o caer en la ilusión de que tiene acceso a un nivel de vida superior, cuando en realidad sus ingresos no han cambiado. De hecho, el servicio financiero formal en estas condiciones compromete los niveles de bienestar futuro de estos hogares por dos vías: a) gasto en rubros de consumo de bajo retorno (baja inversión en capital humano o bienes durables) y b) pago de altos intereses por el financiamiento.

En este marco, el artículo presenta una discusión acerca de los determinantes del proceso de inclusión financiera desde la perspectiva de oferta y demanda de servicios. La evidencia sugiere que el proceso de inclusión financiera tiene una importante dinámica del lado de la oferta de productos y servicios, pero del lado de la demanda las capacidades 
y la cultura financiera - o la acumulación de capital humano- los esfuerzos han sido insuficientes.

La solución que parece más viable para este problema se asocia con el incremento de las capacidades financieras de la población de menos recursos mediante alfabetismo financiero y la promoción del cambio en sus usos y costumbres financieras. La realidad del país pone sobre la mesa la falta de planeación y el hecho de que un ejercicio para el incremento de las capacidades financieras implica la responsabilidad de todos los sectores más allá de intereses y retornos inmediatos. Se necesita no solo un programa de educación, sino la construcción de toda una cultura financiera que parta del buen manejo de las finanzas personales y aterrice en el ámbito de los servicios financieros formales. Por el lado de la oferta, se necesita de un ejercicio de mayor conciencia y responsabilidad de las instituciones financieras en el ofrecimiento de sus productos.

Según el diagnóstico de este trabajo, el proceso de inclusión financieray la estrategia de política pública, en lugar de disminuir la brecha entre los sectores de bajos recursos y los más favorecidos, pueden incrementar las desigualdades. Las autoridades mexicanas han reaccionado lentamente ante las necesidades de educación financiera y los adecuados incentivos que generen cambios desde la administración de las finanzas personales. Se sugiere acompañar los programas de educación financiera con una estrategia conjunta de mejoramiento de la capacidad de cálculo y conocimientos matemáticos básicos. También se propone generar incentivos que involucren al sector laboral en la creación de una cultura para la saludable administración de las finanzas personales.

\section{REFERENCIAS}

1. Alianza para la Inclusión Financiera (AFI) (2011). Measuring financial inclusion. Core set of financial inclusion indicators. Bangkok: Autor.

2. Alonso, G., García, N., Roa, M. y Rodríguez, D. (2014). Educación e inclusión financiera en América Latina y el Caribe. Ciudad de México: CEMLA y Banco de la República de Colombia.

3. Amezcua, E., Arroyo, M. y F. Espinosa (2014). Contexto de la educación financiera en México. Ciencia Administrativa, 1(1), 21-30. https://www.uv.mx/iiesca/files/2014/09/03CA201401.pdf

4. Anderson, T. (1951). Estimating linear restrictions on regression coefficients for multivariate normal distributions. Annals of Mathematical Statistics, 22, 327-351. https://doi.org/10.1214/aoms/1177729580

5. Angrist, J. (2001). Estimation of limited dependent variable models with dummy endogenous regressors. Journal of Business Eु Economic Statistics, 19(1), 2-28. https://doi.org/10.3386/t0248

6. Aportela, F. (1999). Effects of financial access on savings by low-income people. Ciudad de México: Banco de México.

7. Aportela, F. (2001). Efectos de los ciclos de crédito en México sobre la tasa de ahorro de los hogares, 1989-1996 [Documento de investigación 2001-03]. Ciudad de México: Banco de México.

8. Attanasio, O. y Székely, M. (1999). Ahorro de los hogares y distribución del ingreso en México. Economía Mexicana, 3(2), 267-338. http://www.economiamexicana.cide.edu/num_anteriores/VIII-2/03_ORAZIO_ ATTANASIO_267-338.pdf

9. Beck, T., Demirgüç-Kunt, A. y Levine, R. (2007). Finance, inequality and the poor. Journal of Economic Growth, 12(1), 27-49. https://doi.org/10.1007/s10887-007-9010-6

10. Becker, G. y Tomes, N. (1986). Human capital and the rise and fall of families. Journal of Labor Economics, 4(3), 1-39. https://doi.org/10.1086/298118 
11. Bernal, P (2007). Ahorro, crédito y acumulación de activos en los hogares pobres de México. Cuadernos del Consejo de Desarrollo Social, 4. Recuperado de https:/www.coneval.org.mx/sitios/RIEF/Documents/ nuevoleon-estudioahorro-2007.pdf

12. Behrman, J., Mitchell, O., Soo, C. y Bravo, D. (2010). Financial literacy, schooling and wealth accumulation [NBER Working Paper Series 32]. Recuperado de https://repository.upenn.edu/cgi/viewcontent. cgi? article $=1031 \&$ context $=$ parc_working_papers https://doi.org/10.3386/w16452

13. Berti, C. (2001). Poverty traps and human capital accumulation. Economica, 68, 203-219. https://doi. org/10.1111/1468-0335.00242

14. Campos R. y Meléndez, A. (2013). Una estimación semiparamétrica de las pautas de consumo e ingreso a lo largo del ciclo de vida para México. El Trimestre Económico, 80(4), 805-840. https://doi.org/10.20430/ ete.v80i320.104

15. Castellanos, S. y Garrido, D. (2010). Tenencia y uso de tarjetas de crédito en México. Un análisis de los datos de la encuesta nacional de ingresos y gastos de los hogares 2006. El Trimestre Económico, 77(1), 69-103. https://doi.org/10.20430/ete.v77i305.435

16. Ceballos, O. (2018). Perfiles de ahorro y pago de deuda en el ciclo de vida de los hogares mexicanos. El Trimestre Económico, 85(2), 311-339. https://doi.org/10.20430/ete.v85i338.322

17. Comisión Nacional Bancaria y de Valores (CNBV) (2012). Libro blanco de inclusión financiera. Ciudad de México: Autor.

18. Comité Económico y Social Europeo (CESE) (2011). Educación financiera para todos: estrategias y buenas prácticas de educación financiera en la Unión Europea. Bruselas: Autor.

19. Cotler, P. y Rodríguez-Oreggia, E. (2009). Acceso y participación de los sectores populares mexicanos en el mercado formal de crédito. El Trimestre Económico, 76(3), 671-693. https://doi.org/10.20430/ete. v76i303.493

20. Cragg, J. y Donald, S. (1993). Testing identfiability and specification in instrumental variables models. Econometric Theory, Vol. 9, 222-240. https://doi.org/10.1017/s0266466600007519

21. Demirgüç-Kunt, A. y Klapper, L. (2012). Measuring financial inclusion: The global Findex Database [World Bank Policy Research Paper 6025]. Washington: Banco Mundial. https://doi.org/10.1596/1813-9450-6025

22. Demirgüç-Kunt, A. y Levine, R. (2009). Finance and inequality: Theory and evidence [NBER Working Paper Series 15275]. https://doi.org/10.3386/w15275

23. Demirgüç-Kunt, A., Beck, T. y Honohan, P. (2008). Finance for all? Policies and pitfalls in expanding access. Washington: Banco Mundial. https://doi.org/10.1596/978-0-8213-7291-3

24. Duarte, F. y Hasting, J. (2009). Fettered consumer and sophisticated firms: Evidence from Mexico's privatized social security market [NBER Working Paper 18585]. https://doi.org/10.3386/w18582

25. Engel, J. y Kneip, A. (1996). Recent approaches to estimating Engel curves. Journal of Economics, 63(2), 187-212. https://doi.org/10.1007/bf01258672

26. Friedman, M. (1957). A theory of the consumption function. Princeton: Universidad de Princeton.

27. Galor, O. y Zeira, J. (1993). Income distribution and macroeconomics. The Review of Economic Studies, 60(1), 35-52. https://doi.org/10.2307/2297811

28. García, R. (2013). Sobre las curvas de Engel: una breve revisión de su evolución histórica. Ensayos de Economía, 42 (1), 175-189. https://revistas.unal.edu.co/index.php/ede/article/download/41258/42821 
29. González, A. y Villagómez, A. (2014). El efecto del alfabetismo financiero en el ahorro para el retiro en México [Working Papers DTE 576]. Recuperado de https://ideas.repec.org/p/emc/wpaper/dte576.html

30. Hasting, J. y Tejada-Ashton, L. (2008). Financial literacy, information and demand elasticity [NBER Working Paper 14538]. https://doi.org/10.3386/w14538

31. Holzmann, R., Mulaj, F. y Perotti, V. (2013). Financial capability in low and middle-income countries. Washington: Banco Mundial.

32. Koenker, R. y Bassett, G. (1978). Regression quantiles. Econometrica: Journal of the Econometric Society, 46(1), 33-50. https://doi.org/10.2307/1913643

33. Levine, R. (2005). Finance and growth: Theory and evidence [NBER Working Paper 10766]. https://doi. org/10.3386/w10766

34. Liquitaya, J. (2011). La teoría del ingreso permanente: un análisis empírico. Revista Nicolaita de Estudios Económicos, 6(1), 33-61. https://biblat.unam.mx/hevila/Revistanicolaitadeestudioseconomicos/2011/ vol6/no1/2.pdf

35. Lusardi, A y Mitchell, O. (2011). The outlook for financial literacy [NBER Working Paper 17077]. https:// doi.org/10.3386/w17077

36. Lusardi, A. y Mitchell, O. (2014). The economic importance of financial literacy: Theory and evidence. Journal of Economic Literature, 52(1), 5-44. https://doi.org/10.3386/w18952

37. Lusardi, A y Mitchell, O. (2007). Baby boomers' retirement decurity: Rol of planning, financial literacy and housing wealth. Journal of Monetary Economics, 54(1), 205-224. https://doi.org/10.1016/j. jmoneco.2006.12.001

38. Martínez, I. y Villezca, P. (2005). La alimentación en México. Un estudio a partir de la Encuesta Nacional de Ingresos y Gastos de los Hogares y de las Hojas de Balance de la FAO. Ciencia UANL, 8(2), 196-208. https://www.redalyc.org/pdf/402/40280207.pdf

39. Medina, F. (1998). El ingreso y el gasto como medida del bienestar de los hogares: una evaluación estadística. Santiago de Chile: Cepal.

40. Mejía, I. (2008). Ciclo de vida económico en México. En La situación demográfica de México 2008. Santiago de Chile: Cepal.

41. Modigliani, F. y Brumberg, R. (1954). Utility analysis and the consumption function: An interpretation of cross-section data. En K. Kurihara (Ed.), Post keynesian economics (pp. 388-436). New Brunswick: Universidad Rutdgers.

42. Morfín, M. (2009). Banca de desarrollo y el apoyo al acceso (México). Santiago de Chile: Cepal.

43. Muñoz, M. (2004). Determinantes del ingreso y del gasto corriente de los hogares. Revista de Economía Institucional, 6(10), 183-199. https://www.redalyc.org/pdf/419/41901008.pdf

44. Organización para la Cooperación y el Desarrollo Económicos (OCDE) (2015). How’s life 2015? Measuring well-being. París: Autor.

45. Ponce, A., Seira, E. y Zamarripa, G. (2017). Borrowing on the wrong credit card? Evidence from Mexico. American Economic Review, 107(4), 1335-1361. https://doi.org/10.1257/aer.20120273

46. Roa, M. (2013). Inclusión financiera en América Latina y el Caribe: acceso, uso y calidad Ciudad de México: CEMLA.

47. Rodríguez, A. y Dorantes, P. (2016). La reciente reforma financiera en México: transformaciones y perspectivas. Economía UNAM, 13(37), 89-106. https://doi.org/10.1016/j.eunam.2016.02.004 
48. Sánchez B. y Vicéns, J. (2012). Regresión cuantílica: estimación y contrastes. Madrid: Universidad Autónoma de Madrid.

49. Sandoval-Hernandez, J. (2013). Household saving behavior in Mexico: Evidence from cross-sectional analysis and synthetic panels. Charleston: College of Charleston.

50. Schreiner M., Sherraden, M., Clancy, M., Johnson, L., Curley, J., Zhan, M. y Grinstein-Weiss, M. (2001). Asset accumulation in low-resource households: evidence from individual development accounts. Chicago: Banco de Chicago.

51. Secretaría de Hacienda y Crédito Público de México (2011). Acuerdo por el que se crea el Consejo Nacional de Inclusión Financiera. Diario Oficial de la Federación (DOF): 03/10/2011.

52. Urbiola A. (2011). Educación financiera en México: participación de las entidades del sector de ahorro y crédito popular. Estudios Sociales, 8, 202-217.

53. Van Gameren, E. (2008). Labor force participation of Mexican elderly: The importance of health. Estudios Económicos, 23(1), 89-127. https://ideas.repec.org/a/emx/esteco/v23y2008i1p89-127.html

54. Vella, F. (1998). Estimating models with sample selection bias: A survey. The Journal of Human Resources, 33(1), 127-169. https://doi.org/10.2307/146317

55. Villagómez, A. y Zamudio, A. (2000). A dynamic analysis of household decision-making: the Mexican. Washington: BID.

56. Villarreal, F. (2014). Financial services and household inequality in Mexico [Munich MPRA Paper 57075]. Recuperado de http://mpra.ub.uni-muenchen.de/57075/

57. Vonderlack, R. y Schreiner, M. (2001). Mujeres, microfinanzas, y ahorro: lecciones y propuestas. San Luis: Universidad Washington en San Luis.

58. Woodruff C. y Martínez, J. (2009). Evolución de los cambios en el acceso a servicios financieros de los hogares en México: un análisis de la encuesta de panel Bansefi/Sagarpa 2004-2007. Bienestar y Política Social, 5(1), 77-117.

59. Zimmerman, F. y Carter, M. (2003). Asset smoothing, consumption smoothing and the reproduction of inequality under risk and subsistence constraints. Journal of Development Economics, 72, 233-260. https:// doi.org/10.1016/s0304-3878(03)00028-2 